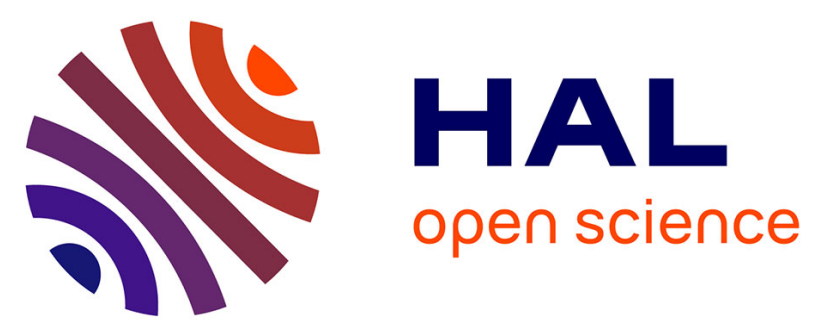

\title{
Theoretical considerations on the modelling of transport in a three-phase electrode and application to a proton conducting solid oxide electrolysis cell
}

\author{
Mikaël Dumortier, José Sanchez, Michel Keddam, Olivier Lacroix
}

\section{- To cite this version:}

Mikaël Dumortier, José Sanchez, Michel Keddam, Olivier Lacroix. Theoretical considerations on the modelling of transport in a three-phase electrode and application to a proton conducting solid oxide electrolysis cell. International Journal of Hydrogen Energy, 2012, 37 (16), pp.11579-11594. 10.1016/j.ijhydene.2012.05.023 . hal-00801838

\section{HAL Id: hal-00801838 \\ https: / hal.sorbonne-universite.fr/hal-00801838}

Submitted on 23 Apr 2015

HAL is a multi-disciplinary open access archive for the deposit and dissemination of scientific research documents, whether they are published or not. The documents may come from teaching and research institutions in France or abroad, or from public or private research centers.
L'archive ouverte pluridisciplinaire HAL, est destinée au dépôt et à la diffusion de documents scientifiques de niveau recherche, publiés ou non, émanant des établissements d'enseignement et de recherche français ou étrangers, des laboratoires publics ou privés. 


\section{Elsevier Editorial System(tm) for International Journal of Hydrogen Energy Manuscript Draft}

\section{Manuscript Number:}

Title: Theoretical considerations on the modelling of transport in a three-phase electrode and application to a proton conducting solid oxide electrolysis cell

Article Type: Full Length Article

Keywords: Mathematical modelling; Electrolysis; Porous media; SOEC

Corresponding Author: Mr Mikael Dumortier,

Corresponding Author's Institution:

First Author: Mikael Dumortier

Order of Authors: Mikael Dumortier; José Sanchez; Michel Keddam; Olivier Lacroix

Abstract: This paper presents a numerical model for fuel cells and electrolysis cells that use cermets as electrodes. The continuity equations for mass and charge are established via a control volume method in order to take into account the variation of metal or ceramic fractions inside the cermet. The Dusty Gas model is used to describe diffusion inside the electrodes and the Brinkman equation is employed for the conservation of momentum inside the fluid phase. The model is tested for the protonconducting SOEC technology on a generic cell design and the calculations are performed with COMSOL Multiphysics $4.1^{\mathrm{TM}}$. A parametric analysis is carried out on a proton-conducting SOEC in galvanostatic mode in order to evaluate the influence of parameters on oxygen production across the electrode in the anodic compartment. 


\section{Mikael Dumortier}

Université Montpellier 2, Bât. 13, 2e étage, Pl. Eugène Bataillon, 34095 Montpellier

$$
+(033) 467149229
$$

mikael.dumortier@iemm.univ-montp2.fr

Dear Mr. Veziroglu,

I am currently preparing my $\mathrm{PhD}$ at the Institut Européen des Membranes in Montpellier, France, on the modeling of proton conducting solid oxide electrolysis cells.

The paper presents a complete numerical model for the prediction of mass and charge transfer inside electrolysis cells and fuel cells working at high temperature and using cermets as electrodes. It also discusses some assumptions taken in fuel cells or electrolysis cells modelling.

I think that the problems dealt in this paper are in perfect match with the topics covered by the International Journal of Hydrogen Energy. Indeed many articles that were published in the journal served as a basis for this work.

Meng Ni, from the University of Hong Kong, M.M Hussain, from the University of Waterloo and Anchasa Pramuanjaroenkija, from the University of Miami, would represent in my view relevant reviewers for this paper. As specialists in fuel cells and electrolysis cells modelling, they can rigorously evaluate the scientific content of this paper. Moreover, several assumptions they use for their models are discussed in the paper.

I am fully available from the first of January to deal with the reports of the reviewers.

I will be pleased to supply any further information should it be required.

Yours sincerely,

Mikael Dumortier 
Demonstration of continuity equations for mass and charge inside a cermet electrode Reversible numerical model for proton and anion conducting SOECs and SOFCs Reaction rate across the anode for position dependent fractions of metal and ceramic Analysis of diffusion of oxygen back to the inlet of the anodic channel of SOECs Use of compressibility factors for the modelling of fuel cells and electrolysis cells 
Theoretical considerations on the modelling of transport in a three-phase electrode and application to a proton conducting solid oxide electrolysis cell

\author{
Mikaël Dumortier ${ }^{\mathrm{a}, \mathrm{c},}$, José Sanchez $^{\mathrm{a}}$, Michel Keddam ${ }^{\mathrm{b}}$, Olivier Lacroix ${ }^{\mathrm{c}}$
}

${ }^{a}$ Institut Européen des Membranes - Université de Montpellier 2, CC 047, 2 Place Eugène Bataillon, 34095 Montpellier

Cedex 5, France

${ }^{b}$ UPMC-CNRS, Laboratoire Interfaces et Systèmes Electrochimiques, cc 133, 4 place Jussieu, 75252 Paris Cedex 5, France

${ }^{c}$ AREVA NP, Centre Technique, UM2 Place Eugène Bataillon Bâtiment 13- ${ }^{2 \grave{m e} e}$ étage 34095 Montpellier Cedex 5, France

*Corresponding author. Tel.: +33 46714929; fax: +33 467149119. E-mail address: mikael.dumortier@gmail.com (J. Sanchez). 


\begin{abstract}
This paper presents a numerical model for fuel cells and electrolysis cells that use cermets as electrodes. The continuity equations for mass and charge are established via a control volume method in order to take into account the variation of metal or ceramic fractions inside the cermet. The Dusty Gas model is used to describe diffusion inside the electrodes and the Brinkman equation is employed for the conservation of momentum inside the fluid phase. The model is tested for the proton-conducting SOEC technology on a generic cell design and the calculations are performed with COMSOL Multiphysics $4.1^{\mathrm{TM}}$. A parametric analysis is carried out on a proton-conducting SOEC in galvanostatic mode in order to evaluate the influence of parameters on oxygen production across the electrode in the anodic compartment.
\end{abstract}




\section{Nomenclature}

$A_{i} \quad$ Gas reactant or product in the half-reaction at an electrode

$C_{T} \quad$ Total concentration $\left(\mathrm{mol} \mathrm{m}^{-3}\right)$

$D_{i} \quad$ Diffusion coefficient for species $i\left(\mathrm{~m}^{2} \mathrm{~s}^{-1}\right)$

$D_{i j} \quad$ Diffusion coefficient of species $i$ inside species $j\left(\mathrm{~m}^{2} \mathrm{~s}^{-1}\right)$

$D_{i, K n} \quad$ Knudsen diffusion coefficient for species $i\left(\mathrm{~m}^{2} \mathrm{~s}^{-1}\right)$

$d_{p} \quad$ Pore diameter $(\mathrm{m})$

$F \quad$ Faraday constant $\left(\mathrm{C} \mathrm{mol}^{-1}\right)$

I $\quad$ Applied electric current (A)

$I_{d} \quad$ Identity matrix (dimensionless)

$i_{r} \quad$ Volumetric transfer current $\left(\mathrm{A} \mathrm{m}^{-3}\right)$

$\vec{j}_{i} \quad$ Charge flux density inside phase $i\left(\mathrm{~A} \mathrm{~m}^{-2}\right)$

$k \quad$ Charge of the ion conducted by the ceramic phase

$L \quad$ Channel characteristic length (m)

$l_{0} \quad$ Reaction length $(\mathrm{m})$

$\dot{m}_{i} \quad$ Mass flow rate of species $i\left(\mathrm{~kg} \mathrm{~s}^{-1}\right)$

$M_{i} \quad$ Molar weight for species $i\left(\mathrm{~kg} \mathrm{~mol}^{-1}\right)$

$M_{I} \quad$ Molar weight of the transported ion $\left(\mathrm{kg} \mathrm{mol}^{-1}\right)$

$M_{i j} \quad$ Harmonic mean molar weight of species $i$ and $j\left(\mathrm{~kg} \mathrm{~mol}^{-1}\right)$

$\vec{n} \quad$ Normal vector (dimensionless)

$\vec{N}_{i} \quad$ Molar flux density for species $i\left(\mathrm{~mol} \mathrm{~s}^{-1} \mathrm{~m}^{-2}\right)$

$P \quad$ Total pressure $(\mathrm{Pa})$

$P e \quad$ Peclet number (dimensionless)

$P_{T P} \quad$ Probability for a triple point to be electrochemically reactive (dimensionless) 


\begin{tabular}{|c|c|}
\hline$R$ & Ideal gas constant $\left(\mathrm{J} \mathrm{mol}^{-1} \mathrm{~K}^{-1}\right)$ \\
\hline$r_{i}$ & Grain radius inside phase $i(\mathrm{~m})$ \\
\hline$r_{r}$ & Total volumetric molar transfer rate $\left(\mathrm{mol} \mathrm{s}^{-1} \mathrm{~m}^{-3}\right)$ \\
\hline$r_{r(i)}$ & Volumetric molar transfer rate for species $i\left(\mathrm{~mol} \mathrm{~m}^{-3} \mathrm{~s}^{-1}\right)$ \\
\hline$S$ & Boundary of the control volume $\left(\mathrm{m}^{2}\right)$ \\
\hline$S_{i}$ & Surface for phase $i\left(\mathrm{~m}^{2}\right)$ \\
\hline$s_{i}$ & Surface fraction for phase $i$ (dimensionless) \\
\hline$t$ & Time (s) \\
\hline$T$ & Local uniform temperature $(\mathrm{K})$ \\
\hline$\vec{u}$ & Velocity vector $\left(\mathrm{m} \mathrm{s}^{-1}\right)$ \\
\hline$U$ & Velocity magnitude $\left(\mathrm{m} \mathrm{s}^{-1}\right)$ \\
\hline$V$ & Volume of the control volume $\left(\mathrm{m}^{3}\right)$ \\
\hline$V_{i}$ & Volume for phase $i\left(\mathrm{~m}^{3}\right)$ \\
\hline$V m_{i}$ & Molar volume of species $i\left(\mathrm{~m}^{3} \mathrm{~mol}^{-1}\right)$ \\
\hline$V m_{m}$ & Molar volume of the mixture $\left(\mathrm{m}^{3} \mathrm{~mol}^{-1}\right)$ \\
\hline$x_{i}$ & Molar fraction for species $i$ (dimensionless) \\
\hline$Z_{i}$ & Compressibility factor for species $i$ (dimensionless) \\
\hline$Z_{i j}$ & Mean compressibility factor of species $i$ and $\mathrm{j}$ (dimensionless) \\
\hline$\alpha$ & Charge transfer coefficient (dimensionless) \\
\hline$[\Gamma]$ & Non-ideality matrix (dimensionless) \\
\hline$\varepsilon_{i}$ & Volumetric fraction of the phase $i$ (dimensionless) \\
\hline$\varepsilon_{\text {reation }}$ & Volumetric fraction of potentially reactive volume (dimensionless) \\
\hline$\Delta_{r}^{0} G$ & Standard molar Gibbs energy of reaction $\left(\mathrm{J} \mathrm{mol}^{-1}\right)$ \\
\hline$\eta$ & Overpotential (V) \\
\hline$\kappa$ & Permeability $\left(\mathrm{m}^{2}\right)$ \\
\hline
\end{tabular}




$\begin{array}{ll}v_{i} & \text { Stoichiometric coefficient for species } i \text { (dimensionless) } \\ \mu_{g} & \text { Dynamic viscosity (Pa s) } \\ \rho_{g} & \text { Gas density }\left(\mathrm{kg} \mathrm{m}^{-3}\right) \\ \rho_{m} & \text { Density of the mixture }\left(\mathrm{kg} \mathrm{m}^{-3}\right) \\ \sigma_{i} & \text { Clectrical conductivity for phase } i\left(\mathrm{~S} \mathrm{~m}^{-1}\right) \\ \sigma_{i j} & \text { Collision diameter for species } i \text { and } j(\mathrm{~m}) \\ \tau & \text { Martuosity (dimensionless) } \\ \varphi_{g} & \text { Charge potential inside phase } i(\mathrm{~V}) \\ \Phi_{i} & \text { Charge production term }\left(\mathrm{C} \mathrm{s}^{-1}\right) \\ \chi_{i} & \text { Charge density inside phase } i\left(\mathrm{C} \mathrm{m}{ }^{-3}\right) \\ \psi_{i} & \text { Collision diffusion integral (dimensionless) } \\ \omega_{i j} & \end{array}$

Numerical analysis

$\begin{array}{ll}\nabla & \text { Del operator } \\ \text { d } & \text { Differential operator } \\ \partial & \text { Partial differential operator } \\ {[]} & \text { Matrix }\end{array}$

Indexes and subscripts

e variable attached to the metallic phase or to charge carried by electrons
ext used for surfaces included in the boundary of the control volume
eff effective value of a variable 
g variable attached to the gas phase

io variable attached to the ceramic phase or to charge carried by ions

int used for surfaces inside the control volume

TP variable attached to the triple phase boundary

0 reference quantity

Abbreviations

DGM Dusty Gas Model

HTE High Temperature Electrolysis

PEMFC Proton Exchange Membrane Fuel Cell

RUC Representative Unit Cell

SOEC Solid Oxide Electrolysis Cell

SOFC $\quad$ Solid Oxide Fuel Cell

ODE Ordinary Differential Equation 


\section{Introduction}

Hydrogen is a promising energy carrier due to its non-polluting combustion which releases only water and a high amount of energy (120 $\left.\mathrm{MJ} \mathrm{kg}^{-1}\right)$ [1]. However, hydrogen gas does not exist naturally on earth and therefore needs to be produced industrially. Today, the hydrogen economy is mainly dependent on hydrocarbons, as it is produced principally through steam reforming [2]. However, hydrogen production from hydrocarbons results in a concomitant production of large amounts of carbon dioxide. Several processes, such as high temperature water electrolysis (HTE), are being developed to obtain mass production of hydrogen independently from oil or to transform carbon dioxide into chemical products with high value. HTE installations can be coupled with existing power plants that release large amounts of heat, which is then used as energy input for the splitting of water [3, 4]. HTE therefore requires less electric power than low temperature electrolysis.

One of the most promising technologies for HTE is the Solid Oxide Electrolysis Cell (SOEC) based on Solid Oxide Fuel Cell (SOFC) technology. The SOEC principle is shown schematically in Figure 1. In this study, the cell is an electrochemical membrane reactor composed of two channels separated by a membrane assembly made of a dense solid oxide layer positioned between porous electrodes. The electrodes are made of cermet, a porous composite material made of solid oxides and metals. In proton conducting cells, steam is fed at the anode and oxidized in the cermet. The reaction produces oxygen that is released into the channel, electrons that are conducted by the metal and protons that are transported into the perovskite. Having passed through the dense membrane, protons recombine with electrons at the cathode to produce pure hydrogen. Conversely, in anion-conducting cells, steam is reduced at the cathode, producing hydrogen and oxygen ions that recombine into oxygen at the anode. 
As ions can only pass through dense solid membranes at relatively high temperatures, electrolysis takes place under hard operating conditions (temperature ranged between $500{ }^{\circ} \mathrm{C}$ and $1000{ }^{\circ} \mathrm{C}[5]$ and pressure from 1 to 100 bar).

As stated above, charge transport inside the solid electrolyte depends on the material that is chosen, whereas the global transport process in porous cermets is much more complex: metal allows electron transport, ions are transferred through the solid oxide phase and gases flow through open pores. The electrochemical reaction occurs at the junction of these three phases, called a triple-phase boundary.

These electrochemical membrane reactors are still at the research stage and their future development requires further efforts in numerical simulation to optimize the heat and mass transfers as well as electrolysis cell design.

Numerous mathematical models have been developed for fuel cells, especially for SOFCs [6] and PEMFCs [7, 8]. Numerical modelling of electrolysis cells is a more recent topic, but the few studies that have been presented use the same approach as for fuel cells. Meng Ni et al [9] developed one of the first SOEC models in 2007; they built a 1D model for a SOEC by integrating a set of ODEs along the electrodes, with assumptions based on the results reported in the literature. This model features no differential equations and can easily be included in engineering numerical codes with user routines such as Fluent ${ }^{\mathrm{TM}}$ or Star-CD ${ }^{\mathrm{TM}}$. It is a very good compromise between precision and time calculation. In 2009 Grondin et al [10] proposed a 3D model including thermal effects, Knudsen diffusion and the generalized Butler-Volmer law. The equation set was solved using the commercial software COMSOL Multiphysics $4.1^{\mathrm{TM}}$. These models are based on regular assumptions when modelling SOFCs. These frequently include the consideration of ideal gases [11]. However, those gases tend to deviate from the ideal gas behaviour at high pressure, especially steam. To assess the effects 
of this simplifying hypothesis, the compressibility factors of gases have been included in the equation of state used in this work.

In terms of electrokinetics, the Butler-Volmer equation is often used to describe the charge transfer at the junction of the three phases. Two forms of this equation are regularly employed in models: the classical Butler-Volmer equation [11], that accounts for the activation effects, and the generalized Butler-Volmer equation [10, 12], that accounts for both activation and concentration effects. The first equation is obtained from the second by considering that the concentrations of chemical species do not vary across the electrode. Inside volumetric electrodes such as cermets, reaction sites are distributed within the entire volume and the electrochemical reaction can take place anywhere in the electrode. However, due to the different transport mechanisms inside the cermet, the reaction rate is higher in some regions of the electrode. Several studies have shown that the reaction rate is higher near the interface between the electrode and the electrolyte. Thus, the reaction domain is often treated as a boundary condition $[9,10,13]$. This assumption is discussed in this paper regarding the choice of the Butler-Volmer equation.

Finally, some studies have considered electrodes in which the size of the particles and the volumetric fraction of each phase can change in depth $[14,15]$. This affects the properties of the medium. To ensure that the effects of such a composition within the model are rigorously taken into account, this paper demonstrates mathematically the local equations inside a three phase electrode, based on a control volume averaging approach [16].

The model aims to be sufficiently general to be applied for both SOECs and SOFCs. Indeed, the fundamental equations describing the phenomena inside SOFCs or SOECs are the same, as one technology is the reverse of the other. From a numerical calculation point of view, only the boundary conditions differ between the two problems. This model is tested throughout a parametric analysis on oxygen production along the anode of a proton- 
conducting cell, involving every type of transport phenomenon. For this we carried out calculations coupling the electrochemical production of oxygen with the mass transport inside the anodic compartment taking in consideration the coupled contribution of diffusion and convection through the Peclet number $(\mathrm{Pe})$.

\section{System of equations}

\subsection{General assumptions}

The following general assumptions were considered when designing the model:

- Steady state

- Isothermal

- Single-step electrochemical transfer

- No deformation of the structure due to pressure effects

- Spherical particles

- Compressibility coefficients dependent on pressure only

- Negligible effects of gravity (weight, natural convection)

- No interfacial ohmic resistance between grains

\subsection{Electrode media description}

The electrodes studied in this paper are cermets, which are considered as one of the most interesting candidates as electrode material for high-temperature steam electrolysis [17]. The cermet is a mixed media made of three phases: an electron-conducting phase, which is usually a metal, an ion-conducting phase, which is usually a ceramic, and a gas phase that allows the transport of reactants and reaction products. The metallic and ceramic phases are motionless and transport charge by migration. Conversely, the gas phases do not carry any charge and 
transport chemical species by diffusion and by convection. These transport phenomena inside the electrode are modelled mathematically by continuity equations obtained by applying the volume averaging method [16] to a representative volume of electrode. This volume comprises both a solid and a fluid phase and defines a mesoscopic volume $V$; this is large enough to smooth the morphological complexities and small enough to capture the global transport properties (i.e. typically a few pore lengths). The scale of the control volume must be smaller than the averaging length of the physical quantities in order to consider that they vary slowly inside the volume.

Normally the balance cannot be written directly on the whole control volume because it contains more than one phase. Therefore, the aim of the demonstration in this paper is to build local equations for the representative volume by writing a balance on the volume of each phase (see Figure 2). Each of these control volumes is bounded by a control surface $S_{i}$, in which normal vector $\vec{n}$ is outer-pointing. The volumetric fraction of each phase can vary inside the electrode. They are written as:

$\varepsilon_{i o}=\frac{V_{i o}}{V} ; \quad \varepsilon_{e}=\frac{V_{e}}{V} ; \quad \varepsilon_{g}=\frac{V_{g}}{V}$

with:

$\varepsilon_{i o}+\varepsilon_{e}+\varepsilon_{g}=1$

Here $V_{i o}, V_{e}$ and $V_{g}$ are the volume of each phase in the representative volume $V$ (see Figure 2) $\varepsilon_{\mathrm{g}}$ is the total porosity. These fractions can depend on the position inside the electrode.

\subsection{Chemical reaction modelling}

The half-reaction in the cermet can be written as:

$\frac{v_{e}}{k} I o^{k}+v_{e} e^{-}+\sum_{i} v_{i} A_{i}=0$ 
It involves an ion $I o$ of charge $k$, gas products or gas reactants $A_{i}$, and electrons, where $v_{\mathrm{e}}$ and $v_{\mathrm{i}}$ are the stoichiometric coefficients for electrons and the species $i$, respectively. For water oxidation for example:

$\mathrm{H}_{2} \mathrm{O} \rightarrow \frac{1}{2} \mathrm{O}_{2}+2 e^{-}+2 \mathrm{H}^{+}$

$v_{e}=-2, k=+1, v_{H 2 O}=+1, v_{O 2}=+1$

This reaction implies that there are charge and mass transfers between the three phases, which are assumed to take place at the triple-phase boundary. The geometrical nature of this zone of transfer is not well known. It can therefore be modelled as a point, a line, a surface or a volume. In calculations where the electrodes are considered as planes, this zone is logically expressed as a surface. In our case, however, it is easier to visualize the charge transfer within a reactive volume than in a reactive surface. Therefore the reactive zone $V_{T P}$ is expressed in cubic metres. It is assumed to be negligible compared with the volume of other phases and can be considered as a fourth phase inside the cermet. The volumetric fraction of $V_{T P}$ is called the specific reactive volume and is noted $\varepsilon_{\mathrm{TP}}$.

$\varepsilon_{T P}=\frac{V_{T P}}{V}$

\subsubsection{Transfer rate variables}

The transfer is initiated by an external electric current or voltage. The rate of the local transfer depends on the kinetics of the charge conduction transport and gas transport competing inside the volumetric electrode. The transfer rate of the electrochemical reaction is represented locally by two variables:

- $i_{r:}$ the volumetric transfer current (in $\mathrm{A} \mathrm{m}^{-3}$ ). This variable expresses the charge quantity that is transferred from one phase to another per second and per unit of 
volume. It is very useful for establishing a relationship between electric current and molar production.

- $r_{r}$ : the volumetric molar transfer rate (in $\mathrm{mol} \mathrm{s}^{-1} \mathrm{~m}^{-3}$ ). This variable expresses the number of moles of electrons that are implied in the half reaction.

The two quantities are related by Faraday's constant $F$ :

$i_{r}=F r_{r}$

\subsubsection{Butler-Volmer equation}

Those two variables are expressed with the generalized Butler-Volmer equation used widely in SOFC modelling to evaluate the single-step electrochemical reaction rate [6]

$r_{r}=r_{r}^{0}\left[\frac{x_{r e d}}{x_{r e d}^{0}} \exp \left(\frac{\alpha v_{e} F}{R T} \eta\right)-\frac{x_{o x}}{x_{o x}^{0}} \exp \left(\frac{-(1-\alpha) v_{e} F}{R T} \eta\right)\right]$

The electric potential difference between the metallic phase and the ceramic phase is called the overpotential and is given by [18]:

$\eta=\left(\phi_{e}-\phi_{e}^{0}\right)-\left(\phi_{i o}-\phi_{i o}^{0}\right)$

with:

$\phi_{e}^{0}=\frac{\Delta_{\mathrm{r}} \mathrm{G}^{0}}{v_{e} F} ; \quad \phi_{i o}^{0}=0$

As a common assumption for fuel cells [19], the charge transfer coefficient $\alpha$ is considered equal to 0.5 .

Some studies have considered other forms of the Butler-Volmer equation that do not feature pre-exponential terms containing out-of-equilibrium concentrations $[6,20,21]$. These forms are normally used when the activation overpotential and the concentration overpotential are calculated separately. In this study, the activation and concentration effects are both contained inside Equation (6). Other authors [13] have considered another expression of the 
overpotential that does not involve the equilibrium potential $\Phi_{e}^{0}$. One argument for preferring the generalized form and the expression of the overpotential described by Equation (7) is to account for the electrochemical reaction having to slow down in the case of steam exhaustion, i.e. when $x_{\text {red }} \approx 0$. Moreover, when no electric current is applied, the generalized form is reduced to a Nernst equation form, which is not the case for the other forms:

$\phi_{e}-\phi_{i o}=\phi_{e}^{0}-\phi_{i o}^{0}+\frac{R T}{v_{e} F} \ln \left(\frac{x_{o x} x_{r e d}^{0}}{x_{o x}^{0} x_{r e d}}\right)$

\subsection{Charge, mass and conservation}

The method that is presented in this paragraph is used for the conservation of charge and mass. The generic form of a conservation equation for a scalar quantity is:

Stock + Flux + Source $=0$

Stock is the temporal variation term, flux is the sum of fluxes of the quantity that enter or leave the control volume and source corresponds to the source of quantity inside the control volume. The method is first applied to the conservation of charge inside the ceramic phase and then extended to mass and charge inside the metallic phase. The demonstration consists of expressing the mass and charge transfer at a global scale with integral equalities; we then use the volume averaging method to approximate the integrals and obtain the continuity equations. As an example, we will detail the method for the conservation of charge inside the ceramic phase and then apply it to the conservation of charge and mass inside the other phases.

\subsubsection{Integral form}

The conservation of charge inside the ceramic phase is written as:

$\frac{\partial}{\partial t} \iiint_{V i o} \psi_{i o} d V_{i o}+\iint_{S i o} \vec{J}_{i o} d S_{i o} \vec{n}=0$ 
where $\psi_{i o}$ is the ionic charge density $\left(\mathrm{C} \mathrm{m}^{-3}\right)$ and $\vec{\jmath}_{i o}$ the ionic charge flux density $\left(\mathrm{A} \mathrm{m}^{-2}\right)$.

This integral equation is expressed on the control volume of the ionic conductor only. Several geometrical operations are therefore needed to express a local equation on the control volume that includes all the physical phases. To express the flux term, the control surface of the phase is split into two surfaces, as shown in Figure 3:

$S_{i o}=S_{i o}(i n t)+S_{i o}(e x t)$

$S_{\text {io }}($ ext $)=$ Sio $\cap S$

$S_{\text {io }}($ int $)=$ Sio $-($ Sio $\cap S)$

Neglecting the contact area between the conductors gives:

$S_{g}(i n t)=S_{e}(i n t)+S_{i o}(i n t)$

\subsubsection{Phase source terms}

During the electrochemical reaction, charge is transferred between the ceramic phase and the metallic phase. On the whole, however, no charge is created inside the control volume, hence:

$\chi_{e}=-\chi_{i o}=-v_{e} i_{r} V_{T P}$

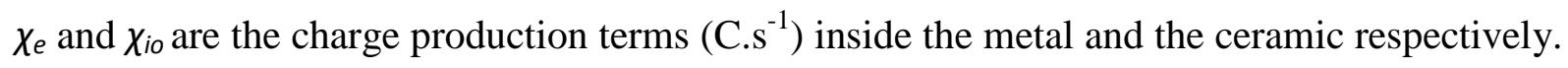
This production takes place inside the reactive volume $V_{T P}$.

By neglecting the mass of electrons, the change in mass inside the gas is equal to the mass of the ions transferred from the ceramic phase to the gas phase. Hence:

$\varphi_{g}=-\frac{\chi_{i o} M_{I}}{F}=-\frac{v_{e}}{k} M_{I} r_{r} V_{T P}$

where $\varphi_{\mathrm{g}}$ is the mass source $\left(\mathrm{kg} \mathrm{s}^{-1}\right)$ in the gas and $M_{I}$ the molar mass of the ion. 


\subsubsection{Flux term}

Following the additivity of integration on intervals, the flux term can be written on each sub-surface:

$\iint_{S_{i o}} \vec{J}_{i o} d S_{i o} \vec{n}=\iint_{S_{i o}(e x t)} \vec{J}_{i o} d S_{i o} \vec{n}+\iint_{S_{i o}(i n t)} \vec{j}_{i o} d S_{i o} \vec{n}$

The last term, integrated on $S_{i o}(i n t)$, corresponds to the charge exiting the electronic conductor and entering the reactive volume because of the reaction. It can be treated as a source term:

$\iint_{S_{i o}(i n t)} \vec{J}_{i o} d S_{i o} \vec{n}=-\chi_{i o}$

The normal vector of the volume is outer-pointed, hence the minus sign. The term integrated on $S_{i o}($ ext $)$ must be expressed on the control surface $S$ using integration by substitution. Before that, another decomposition of the geometrical surfaces is needed.

The sum of the external surfaces is equal to the surface of the representative volume:

$S=S_{g}(e x t)+S_{e}(e x t)+S_{i o}(e x t)$

For each phase, the external surface fraction is defined as:

$s_{i}=\frac{S_{i}(e x t)}{S}$

Assuming that this fraction does not vary with a change in the control surface, the differential form of this equation gives:

$d s_{i}=\frac{d s_{i}(e x t)}{d s}$

Using integration by substitution, the expression of the integral on the whole external surface is given by:

$\iint_{S_{i o}(e x t)} \vec{J}_{i o} d S_{i o} \vec{n}=\oiint_{S} \vec{J}_{i o} S_{i o} d S \vec{n}$

This integral can be written on the representative volume by using Ostrogradsky-Gauss theorem [22]:

$\oiint_{S} \vec{J}_{i o} s_{i o} d S \vec{n}=\iiint_{V} \nabla \cdot\left(\vec{J}_{i o} s_{i o}\right) d V$ 
Ultimately, considering the definition of the representative volume (see $§ 2.2$ ):

$\iiint_{V} \nabla \cdot\left(\vec{J}_{i o} s_{i o}\right) d V \approx \nabla \cdot\left(\vec{J}_{i o} s_{i o}\right) V$

$\nabla$ is the Del operator. It is written $\nabla=\left(\frac{\partial}{\partial x}, \frac{\partial}{\partial y}, \frac{\partial}{\partial z}\right)$ in the Cartesian base.

\subsubsection{Internal variation term}

Using integration by substitution:

$\frac{\partial}{\partial t} \iiint_{V i o} \psi_{i o} d V_{i o}=\frac{\partial}{\partial t} \iiint_{V} \psi_{i o} \varepsilon_{i o} d V$

And again considering the definition of the representative volume we obtain:

$\frac{\partial}{\partial t} \iiint_{V} \psi_{i o} \varepsilon_{i o} d V \approx \frac{\partial\left(\psi_{i o} \varepsilon_{i o}\right)}{\partial t} V$

\subsubsection{Equations for mass and charge}

Ultimately, the continuity equation of the ionic charge inside the representative volume is obtained by coupling equations (9), (19), (25) and (27) and dividing by $V$ :

$\frac{\partial\left(\psi_{i o} \varepsilon_{i o}\right)}{\partial t}+\nabla .\left(\vec{J}_{i o} s_{i o}\right)=v_{e} i_{r} \varepsilon_{T P}$

The conservation of mass and the conservation of electronic charge inside the representative volume are built by following the same analysis. The continuity equation for electronic charge conservation is therefore written as:

$\frac{\partial\left(\psi_{e} \varepsilon_{e}\right)}{\partial t}+\nabla \cdot\left(\vec{J}_{e} s_{e}\right)=-v_{e} i_{r} \varepsilon_{T P}$

where $\psi_{e}$ is the electronic charge density $\left(\mathrm{C} \mathrm{m}^{-3}\right)$ and $\vec{\jmath}_{e}$ is the electronic charge flux density $\left(\mathrm{A} \mathrm{m} \mathrm{m}^{-2}\right)$

The electronic potentials are related to charge fluxes by Ohm's law:

For the ceramic phase: $\quad \vec{J}_{i o}=-\sigma_{i o} \nabla \phi_{i o}$

For the metallic phase: $\quad \vec{\jmath}_{e}=-\sigma_{e} \nabla \phi_{e}$ 
In Equations (30) and (31), the conductivity terms $\sigma_{i o}$ and $\sigma_{e}$ reflect at the same time the intrinsic contribution of the materials and the non-explicit topography of the grain-to-grain contacts. No charge or mass is created inside the control volume, so the source terms are equal to zero. The next paragraph will show that source terms appear when dealing with the equation for phases.

The continuity equation for mass can then be written as:

$\frac{\partial\left(\rho_{g} \varepsilon_{g}\right)}{\partial t}+\nabla \cdot\left(\rho_{g} \vec{u} s_{g}\right)=-\frac{v_{e}}{k} M_{I} r_{r} \varepsilon_{T P}$

where $\rho_{g}$ is the density $\left(\mathrm{kg} \cdot \mathrm{m}^{-3}\right)$ and $\vec{u}$ the velocity vector inside the fluid phase $\left(\mathrm{m} \mathrm{s}^{-1}\right)$.

\subsubsection{Mass conservation for chemical species}

The mathematical treatment for species is more complex. The analysis starts with the conservation of mass in the gas phase, which is given by:

$\frac{\partial}{\partial t} \iiint_{V_{g}} \rho_{g} d V_{g}+\iint_{S_{g}} \rho_{g} \vec{u} d S_{g} \vec{n}=-\frac{v_{e}}{k} M_{I} r_{r} V_{T P}$

The mass flux across the control surface is equal to the sum of the mass flux of the species:

$\sum_{i} \iint_{S_{g}} M_{i} \overrightarrow{N_{\iota}} d S_{g} \vec{n}=\iint_{S_{g}} \rho_{g} \vec{u} d S_{g} \vec{n}$

Using the same analysis as above for equations (33) and (34), the local equation for species is:

$\frac{\partial\left(\rho_{g} \varepsilon_{g}\right)}{\partial t}+\sum_{i} M_{i} \nabla \cdot\left(s_{g} \overrightarrow{N_{l}}\right)=-\frac{v_{e}}{k} M_{I} r_{r} \varepsilon_{T P}$

The idea now is to express a continuity equation of mass for each species. The sum of individual volumetric molar productions is linked with the mass source term:

$\sum_{i} M_{i} r_{r(i)}=-\frac{v_{e}}{k} M_{I} r_{r} \varepsilon_{T P}$

Here $r_{r(i)}$ is the volumetric molar production for species $i$ inside the control volume $\left(\mathrm{mol} \mathrm{m}^{-3} \mathrm{~s}^{-}\right.$

1). Hence: 
$\frac{\partial\left(\rho_{g} \varepsilon_{g}\right)}{\partial t}+\sum_{i} M_{i}\left[\nabla \cdot\left(s_{g} \vec{N}_{l}\right)-r_{r(i)}\right]=0$

The stoichiometry of the reaction gives:

$\frac{r_{r(i)}}{v_{i}}=\frac{r_{r(j)}}{v_{j}}$

and the conservation of mass during the reaction gives:

$\sum_{i} M_{j} v_{j}+\frac{v_{e}}{k} M_{I}=0$

In this equation the mass of the electrons is ignored. Ultimately, using Equations (38) and (39), the molar production of the species $i$ simplifies to:

$r_{r(i)}=v_{i} r_{r} \varepsilon_{T P}$

Assuming steady state and coupling, Equation (40) and Equation (37) give:

$\nabla \cdot\left(s_{g} \overrightarrow{N_{l}}\right)=v_{i} r_{r} \varepsilon_{T P}$

Note: It is possible to obtain the equation in non-steady state by using the relationship between the density of the gas mixture and the concentration of the species presented in $\$ 2.7$.

\subsection{Diffusion model}

The objective is to relate the concentration of species to their fluxes. As the model is applied to a porous media, the Knudsen diffusion regime must be envisaged if the pore radius is small enough. Moreover, the model must take into account the multi-component and nonideal nature of the mixture. The Dusty Gas Model (DGM) has been shown to be a relevant model for describing the diffusion of species inside a volumetric electrode [23]. The matricial form of the DGM has been reported by Krishna and Wesselingh [24]. Solving this system often requires the use of numerical methods; however, for a mixture composed of only two species, it is possible to reduce the DGM to a simpler form, close to Fick's equation:

$\overrightarrow{N_{l}}=-D_{i} \nabla x_{i} C_{T}+x_{i} \cdot C_{T} \cdot \vec{u}$ 
where $\vec{N}_{l}$ is the molar flux of the species $i$ (in mol m $\mathrm{m}^{-2} \mathrm{~s}^{-1}$ ), $D_{i}$ the diffusion coefficient of the species $i\left(\right.$ in $\left.\mathrm{m}^{2} \mathrm{~s}^{-1}\right), x_{i}$ the volumetric fraction of the species $i$ and $C_{T}$ the total concentration of the mixture $\left(\mathrm{mol} \mathrm{m}^{-3}\right), \vec{u}$ is the velocity vector in the mixture.

The non-ideality matrix used in the Dusty Gas model involves compressibility factors for gases. In this study, it is assumed that the compressibility factor for the species $i$ has little dependence on its molar fraction. Hence the non-ideality matrix reduces to the identity matrix:

$[\Gamma]=I_{d}$

By inverting the matrix system for two species, the expression of the diffusion coefficient for the species $i$ is given by:

$D_{i}=\frac{D_{i, K n}^{e f f} D_{i j}^{e f f}}{D_{i j}^{e f f}+x_{j} D_{i, K n}^{e f f}+x_{i} D_{j, K n}^{e f f}}$

For $x_{j} \approx 1$ ( $j$ being the solvent), this expression reduces to Bosanquet's formula, which is often used when the Knudsen diffusion is taken into account [23, 25, 26]:

$D_{i}=\frac{D_{i, K n}^{e f f} D_{i j}^{e f f}}{D_{i, K n}^{e f f}+D_{i j}^{e f f}}$

$D_{i j}^{e f f}$ is the effective binary diffusion coefficient between species $i$ and $j\left(\mathrm{~m}^{2} \mathrm{~s}^{-1}\right)$. It is calculated with the formula adapted from [27] for non-ideal gases with SI units and compressibility factors:

$D_{i j}^{e f f}=8.41 \times 10^{-23} \frac{\varepsilon_{g}}{\tau} \frac{Z_{i j} T^{3 / 2}}{M_{i j}^{1 / 2} P \sigma_{i j}^{2} \omega_{i j}}$

with

$M_{i j}=\frac{2}{1 / M_{i}+1 / M_{j}}$

$\sigma_{i j}$ and $\omega_{i j}$ are evaluated with the data and formulae presented in [27] and [28]. Note that the mixture composed of steam and oxygen at the anode is supposed to be a polar gas, 
hence the calculations of its kinetic properties differ from those of hydrogen, which is non polar.

$D_{i, K n}^{e f f}$ is the effective Knudsen diffusion coefficient for the species $i\left(\mathrm{~m}^{2} \mathrm{~s}^{-1}\right)$. It is calculated with the formula presented in [24]:

$D_{i, K n}^{e f f}=\frac{d_{p}}{3} \frac{\varepsilon_{g}}{\tau} \sqrt{\frac{8 R T}{\pi M_{i}}}$

The tortuosity is evaluated with the RUC model [29]:

$$
\tau=\frac{\varepsilon_{g}}{\left(1-\varepsilon_{g}\right)\left(1-\sqrt{1-\varepsilon_{g}}\right)+\varepsilon_{g}\left(1-\left(1-\varepsilon_{g}\right)^{2 / 3}\right)}
$$

\subsection{Momentum}

The conservation of momentum for flows throughout porous media is very well described by the Darcy-Brinkman equation, expressed in our case [16].

$\frac{\rho_{g}}{\varepsilon_{g}}\left[(\vec{u} . \nabla) \frac{\vec{u}}{\varepsilon_{g}}\right]=\nabla \cdot\left[-P \cdot I_{d}+\frac{\mu_{g}}{\varepsilon_{g}}\left(\nabla \vec{u}+(\nabla \vec{u})^{T}\right)-\frac{2}{3} \frac{\mu_{g}}{\varepsilon_{g}}(\nabla \cdot \vec{u}) I_{d}\right]-\left(\frac{\mu_{g}}{\kappa}+\frac{v_{e}}{k} M_{I} r_{r} \varepsilon_{T P}\right) \vec{u}$

This equation is already implemented in COMSOL Multiphysics $4.1^{\mathrm{TM}}$. The permeability $\kappa$ is evaluated via the Kozeny-Carman equation [30].

\subsection{Porous media}

The different variables required to describe the geometric aspects of the porous media are taken from the work presented by Chen et al. in [31]. The surface fraction and the pore radius are given by:

$s_{i}=\frac{\varepsilon_{i} / r_{i}}{\varepsilon_{i o} / r_{i o}+\varepsilon_{e} / r_{e}+\varepsilon_{g} / r_{g}} ; \quad \quad r_{g}=\frac{2}{3}\left(\frac{1}{\varepsilon_{i o} / r_{i o}+\varepsilon_{e} / r_{e}}\right)$

Following the analysis of Costamagna et al [32] on the application of percolation theory for SOFCs, an expression is built to estimate the value of the specific reactive volume. 
$\varepsilon_{T P}=\varepsilon_{\text {reaction }} P_{T P}$

$P_{T P}$ is the probability that the three-phase boundary is electrochemically reactive and $\varepsilon_{\text {reaction }}$ is the geometric extent of the reactive volume. The works in the literature usually define the reactive area as a line and calculate the triple boundary layer as a proportion of the contact perimeter between ceramic and metallic grains. Methods to calculate those quantities are given in [31].

In this study $\varepsilon_{\text {reaction }}$ is considered as a specific volume, extending from the junction line of the three phases to a characteristic "reaction length", $l_{0}$, which represents the distance between grains within which the steam molecules can react:

$\varepsilon_{\text {reaction }}=\frac{3}{2} \frac{\min \left(r_{i o}, r_{e}\right)}{r_{i o}^{3}} l_{0}^{2}$

This length is not known theoretically and is evaluated as $l_{0}=10^{-8} \mathrm{~m}$, which is approximately a hundred times the length of molecular bonds [33]. The value of this length or the choice of the nature of the triple boundary zone has no impact on local production of mass or charge on the control volume.

\subsection{Properties of the gas mixture}

Compressibility factors are obtained via a linear regression from the data taken from [34-37]:

$Z_{H 2 O}=-4.90 \times 10^{-9} P+1$

$Z_{\text {H2O }}=2.23 \times 10^{-9} \mathrm{P}+1$

$Z_{O 2}=2.82 \times 10^{-9} \mathrm{P}+1$

The compressibility factor and the molar volume are related to the properties of the chemical species using Kay's rule [28]:

$V_{m m}=\sum_{i} x_{i} V_{m i}$

$Z_{m}=\sum_{i} x_{i} Z_{i}$ 
The conservation of mass then gives:

$M_{m}=\sum_{i} x_{i} M_{i}$

Coupling the ideal gas adapted for real gases with the previous equations gives:

$\rho_{m}=\frac{C_{T} M_{m}}{Z_{m}}$

Given the lack of efficient models to calculate the viscosity of polar gas at high pressure [28], the viscosity of the mixture is assumed to be the viscosity of the predominant fluid species in the electrode.

\subsection{Range of validity of the model}

This model has a wide range of applications: it can be used for any type of SOFC or SOEC that respects the assumptions presented in $\S 2.1$. The model is tested on a protonconducting SOEC whose principle is shown in Figure 1.

\section{Numerical model}

The planar SOEC is built in 2D. Indeed, the hydraulic regime considered is laminar; hence the $3 \mathrm{D}$ effects due to turbulence are ignored in the $\mathrm{z}$ direction.

\subsection{Geometry}

The electrolyser geometry considered here is presented in Figure 4. The channels are $0.4 \mathrm{~mm}$ wide, the electrodes are $0.15 \mathrm{~mm}$ wide and the electrolyte is $0.1 \mathrm{~mm}$ thick. The channels are longer than the electrode to observe the mixing along the channel. This geometry is not intended to represent a real SOEC; it is designed in a simple manner to focus on the physical phenomena. The model has been solved using COMSOL Multiphysics $4.1^{\mathrm{TM}}$. The 
species balance equation and the diffusion equation is solved using the "Species transport in porous media" node. Mass and momentum conservation are solved with the "Free and porous media flow" node. Charge conservation is solved using the Poisson's equation in the "PDE node".

As COMSOL Multiphysics 4.1 $1^{\mathrm{TM}}$ does not allow the introduction of boundary conditions at the electrode/electrolyte interface for the ionic and the electronic potential, the electrodes and the electrolyte are modelled as a single domain for the charge equation. In this domain, the volume fractions vary as a function of space. Therefore, the electrolyte is defined where $\varepsilon_{\mathrm{io}}=1$, the channel is defined where $\varepsilon_{\mathrm{g}}=1$, and the electrodes are defined where $\varepsilon_{\mathrm{e}} \neq 0$. Instead of declaring multiple domains with multiple sets of equations, the charge balance is solved with one set of equations all over the domain. The counterpart of such a strategy is that the mesh must be very refined where the volume fractions vary dramatically, i.e. at electrode interfaces. In the electrolyte, $\varepsilon_{T P}$ cannot be calculated and must be specified. Any value can fit, as the exchange current density and thus the mass production term is equal to zero. Numerically speaking, however, the value of $\varepsilon_{T P}$ must be kept at a very low value to avoid oscillations of the electric potential at the boundary between the electrodes and the electrolyte. The reactor dimensions are presented in Table 1.

\subsection{Boundary conditions}

The boundary conditions are presented graphically in Figure 4 and specified in Table 2. For the calculations, inlet velocity and pressure are considered as the same at the cathode channel and at the anode channel.

The calculation is performed in galvanostatic mode and the global reaction rate is imposed by the value of the electric current; this is equal to the product of the current density input by the surface to which it is applied. In addition, the inlet velocity is calculated in order 
to avoid steam depletion, which means that there will always be enough steam available for the electrochemical reaction. The minimum mass flux needed to avoid steam depletion at electrodes is given by:

$\dot{m}_{\mathrm{H}_{2} \mathrm{O}}=\left|\frac{M_{\mathrm{H}_{2} \mathrm{O}} \mathrm{O}}{x_{\mathrm{H}_{2} \mathrm{O}}^{0}} \frac{I}{F} \frac{v_{\mathrm{H}_{2} \mathrm{O}}}{v_{e}}\right|$

\subsection{Mesh}

Various meshes have been used for the calculation. All of them are refined near the boundaries where the concentration and hydraulic gradients are high. The mesh must also be more refined inside the electrodes, as the distribution of reaction kinetics along them is unknown. One of the meshes used contains 20696 elements with an average element of 0.9 ( 0.96 for the triangular elements only).

\subsection{Reference calculation}

Physical constant and other parameters presented in Table 3 are kept constant in the calculations. The values of the physical quantities whose variation are studied are compiled in Table 4.

\section{Results and discussion}

The mass production of a chemical species is imposed by the inlet electric current:

$\dot{m}_{i}=M_{i} \frac{I}{F} \frac{v_{i}}{v_{e}}$

This equation shows that in galvanostatic mode, the electric current is the only parameter influencing mass production. However other parameters such as particle radius, metal fraction and inlet oxygen molar fraction will have an influence on the distribution of this production across the electrode. The relevant variable to study the influence of parameters on this 
distribution is the product of the specific reactive volume $\varepsilon_{T P}$ by the transfer current density $i_{r}$. Indeed, Equations (5) (40) and (63) show that this product is related both to the local mass production and to the inlet electrical current $I$. The integral of this product across the cermet is fixed by the electrical current but its local value depends on the parameter values.

$I=\int_{V_{\text {cermet }}} \varepsilon_{T P} i_{r} d V_{\text {cermet }}$

This product has therefore been chosen as the most suitable variable for a parametric analysis to evaluate the importance of parameters on the distribution of oxygen production across the anode. This analysis has been carried out along the anode, where every type of transport phenomenon is involved, unlike the cathode, where there is no multicomponent gas transport. It can be used in electrode design as a guide to choose the properties of cermets and optimize the yield of the electrolyser or the durability of electrodes. The analysis started with the electrochemical parameters (form of Butler-Volmer equation, electrical conductivity); we then studied the influence of structural parameters (volume fractions and particle radius), ending with the process operating parameters.

\subsection{Form of the Butler-Volmer equation}

When using the Butler-Volmer law with no concentration factor, the oxygen production is close to the electrolyte/electrode interface. In this case, the energy loss of the system is minimal if the protons are conveyed over the shortest distance possible, as the ionic conductivity of ceramics is lower than the electrical conductivity of metal. When using the generalised Butler-Volmer equation, the concentration effects compete with the ohmic drop effects. The oxygen production rate along the anode becomes oxygen concentration dependent, which makes the problem far more complex. The fact that the distribution of oxygen production along the anode moves to the electrode/channel interface (see Figure 5) is explained by the fact that the difference between oxygen and steam concentration decreases as 
steam penetrates deeper into the electrode. As the two profiles are different, the assumptions concerning pre-exponential terms containing out-of-equilibrium concentrations in the ButlerVolmer equation should be justified by comparing concentration with electrical potential effects.

\subsection{Effect of conductivity}

Figure 6 shows that the distribution of oxygen production inside the electrode is less dependent on the value of the conductivities than on the value of their ratio. Indeed, the system tends to distribute oxygen production over the anode in order to minimize energy losses caused by Joule's effect.

- When $\sigma_{e}>\sigma_{i o}$, Joule's effect is mainly caused by the conduction of protons inside the ceramic. The energy loss in the system is minimal at the shortest distance covered by protons,i.e. when they are produced near the electrode/electrolyte interface.

- When $\sigma_{e}<\sigma_{i o}$, Joule's effect is mainly caused by the conduction of electrons inside the metal. The energy loss in the system is minimal at the shortest distance covered by electrons, i.e. when they are produced near the electrode/channel interface.

- When $\sigma_{e}=\sigma_{i o}$, the distribution of oxygen production along the electrode is not symmetrical because of the concentration effects implied by the generalized ButlerVolmer law.

\subsection{Effect of metal volume fraction}

Metal and ceramic volume fractions, along with particle radius are involved in the definition of the specific reactive volume $\varepsilon_{T P}$ and the specific metal surface fraction $s_{e}$. As a result, a change in the fractions has an impact on percolation and on the reaction rate. In this 
calculation, the porosity $\varepsilon_{g}$ remains constant, equal to $1 / 3$. Also, the metal volume fraction $\varepsilon_{e}$ varies across the electrode according to different trends (see Figure 7). In each case, the mean value of the metal volume fraction $\varepsilon_{e}$ is equal to $1 / 3$.

Figure 8 shows that the specific reactive volume $\varepsilon_{T P}$ does not vary monotonously at the same time as the metal fraction $\varepsilon_{e}$, which is consistent with the models taken with the percolation theory for $P_{T P}$ in $\S 2.7$. When a critical volume fraction of metal is reached, the chain of metal grains or ceramic grains that allow the conduction of charges is interrupted. The electric or the ionic current can no longer be conveyed and the specific reactive volume $\varepsilon_{T P}$ becomes equal to zero. For example, oxygen production for the metal fraction profile called decreasing + shows three regions (Figure 9). Near the channel, with a high metal fraction, electrons are conducted in the metal phase, but there is no reaction because the ceramic fraction is too low to reach the ceramic percolation threshold. In the middle of cermet, both metal and ceramic percolate, electrons and protons can be conducted in their respective phases and the electrochemical reaction occurs. Near the electrolyte, with a low metal fraction, electrons are not conducted through metal as it no longer percolates, but the protons are conducted to the electrolyte as the ceramic percolates. Hence, along with the knowledge of percolation threshold, the metal fraction or the ceramic fraction can be adjusted in order to control the reaction rate inside the electrode. This limits significant and localized heat release or electrode assembly delaminating due to peaks of oxygen production near the interfaces.

\subsection{Effect of grain radius}

Grain radius has a significant impact on the properties of the porous medium, such as the specific reactive volume $\varepsilon_{T P}$, the surface fraction, grain coordination and pore diameter. In this study, the radius of ceramic grain is fixed and the radius of metallic grains is a multiple of 
the latter. Figure 10 shows that when this ratio increases, the distribution of oxygen production along the anode flattens.

Indeed, when the radius increases the specific surface of metal $s_{e}$ decreases. Thus, the area of metal available for conduction of electrons gets lower. Because the electric current is fixed, both the electronic current density and the ohmic losses increase. As the effective conductivity of metal gets lower, the system transfers the charge quicker from the metal to the ceramic. This explains why the distribution of oxygen production flattens when the radius of metal grain increases.

\subsection{Effect of inlet oxygen volume fraction}

It is important to study the impact of inlet oxygen volume fraction. Indeed, producing steam by vaporization of liquid water is costly in terms of energy. Instead of feeding the electrolyser with pure steam, it could be possible to recycle the steam that has not reacted and which is enriched in oxygen (see Figure 11).

Figure 12 shows that increasing the inlet oxygen volume ratio lowers oxygen production in the centre of the electrode and increases oxygen production at the sides of the electrodes. There are two reasons for this phenomenon: firstly, when the oxygen fraction increases, the difference of concentration that drives the reaction decreases and concentration effects are therefore less significant than electrical effects. That is why oxygen production becomes higher on the electrolyte side. Secondly, under the operating conditions used for this calculation, the diffusion coefficient of oxygen is lower than steam. Hence the transport of gases is more difficult inside the electrode and consequently the system loses less energy if the reaction occurs without crossing the electrode. That is why oxygen production becomes higher on the channel side. This calculation was performed with an inlet velocity of $0.001 \mathrm{~m}$ $\mathrm{s}^{-1}$ in order to avoid steam depletion. 


\subsection{Effect of operating pressure}

Operating pressures from 10 bar to 30 bar have been tested in the calculations. However, operating pressure does not have a major influence on the distribution of oxygen production across the anode.

\subsection{Effect of inlet velocity}

The parametric calculation showed that the value of velocity does not have an important influence on the distribution of oxygen production across the anode for the values that have been tested $\left(0.0001 \mathrm{~m} \mathrm{~s}^{-1}\right.$ to $\left.0.1 \mathrm{~m} \mathrm{~s}^{-1}\right)$.

However, depending on the value of the Peclet number inside the anodic channel, the oxygen that is released out from the porous anode can flow back to the inlet or be carried out by the water vapour flow (see Figure 13). The expression of the Peclet number is given by:

$P e=\frac{U_{0} L}{D_{O_{2}}}$

If $P e<0.02$, then diffusion transport overcomes convection transport and oxygen flows back to the inlet. On the contrary, if $P e>0.02$, then convection transport overcomes diffusion transport and oxygen is carried by the flow to the outlet. As a result, the value of velocity must be high enough not only to avoid depletion, but also to avoid this counter-diffusion effect. The condition at the inlet velocity is therefore given by:

$U_{0} \geq \max \left(\left|\frac{M_{\mathrm{H}_{2} \mathrm{O}}}{x_{\mathrm{H}_{2} \mathrm{O}}^{0} \rho_{\mathrm{H}_{2} \mathrm{O}}} \frac{I}{F} \frac{v_{\mathrm{H}_{2} \mathrm{O}}}{v_{e}}\right|, \frac{0.02 D_{\mathrm{O}_{2}}}{L}\right)$

\section{Conclusion}

This paper has presented a series of studies that helps to predict a wide range of transport and transfer phenomena inside an anion-conducting SOEC and a proton-conducting SOEC. 
- A set of continuity equations was rigorously demonstrated for the conservation of quantities and for the DGM applied for two species. This set of equations also takes into account the non-idealities of gases under strong operating conditions and the concentration coefficient inside the Butler-Volmer equation.

- A numerical model considering the electrodes and the electrolyte as a single reacting medium in which the metal and the ceramic fractions vary was successfully implemented in the commercial software COMSOL Multiphysics 4.1 1 TM

- A parametric analysis showed that the electrochemical reaction can be distributed all over the anode. Hence the thin layer assumption is not always valid and must be checked numerically. A parametric analysis showed that the parameters of the process have an influence on the distribution of oxygen production along the anode and that electrode structural parameters such as metal fraction or grain radius have a major impact on the oxygen production profile across the anode.

The calculations also showed that the necessity to include the concentration coefficients inside the Butler-Volmer equation and that inlet velocity is an important parameter to be monitored. It must be high enough to avoid steam depletion and to avoid the diffusion of produced oxygen back to the inlet. Three points must be mentioned: firstly, the interaction between the ionic conductivity of ceramics and pressure is not yet taken into account in the model. Secondly, a parameter without influence on the distribution of oxygen production can be influential on the overpotential or on other phenomena like velocity on the diffusion of oxygen in the channel. It is thus important to determine the significance of the quantity that is monitored in the problem. Thirdly, no thermal effects are considered for now. Their consequences on transport phenomena will be assessed in a future work. 


\section{Acknowledgements}

This work was supported by the Agence Nationale de la Recherche. 


\section{References}

[1] M.W. Chase, C.A. Davies, J.R. Downey, J. Phys. Chem. Ref. Data, Monograph(9) (1998) $1-1951$.

[2] M. Ni, Int. J. Hydrogen Energy, 34 (2009) 7795-7806.

[3] V. Utgikar, T. Thiesen, Int. J. Hydrogen Energy, 31 (2006) 939-944.

[4] R. Rivera-Tinoco, C. Mansilla, C. Bouallou, Energy Convers. Manage., 51 (2010) 26232634.

[5] L. Mingyi, Y. Bo, X. Jingming, C. Jing, J. Power Sources, 177 (2008) 493-499.

[6] M. Andersson, J. Yuan, B. Sundén, Appl. Energy, 87 (2009) 1461-1476.

[7] C. Siegel, Energy, 33 (2008) 1331-1352.

[8] D. Cheddie, N. Munroe, J. Power Sources, 147 (2005) 72-84.

[9] M. Ni, M.K.H. Leung, D.Y.C. Leung, Electrochim. Acta, 52 (2007) 6707-6718.

[10] D. Grondin, J. Deseure, M. Zahid, A. Brisse, P. Ozil, J. Appl. Electrochem., 40 (2009) 933-941.

[11] S. Kakaç, A. Pramuanjaroenkij, X.Y. Zhou, Int. J. Hydrogen Energy, 32 (2007) 761-786.

[12] F. Coeuret, A. Storck, Elements de génie électrochimique, Technique et documentation, Paris, 1993.

[13] M.M. Hussain, X. Li, I. Dincer, J. Power Sources, 161 (2006) 1012-1022.

[14] J. Deseure, Y. Bultel, L. Dessemond, E. Siebert, Electrochim. Acta, 50 (2005) 20372046.

[15] J. Deseure, L. Dessemond, Y. Bultel, E. Siebert, J. Eur. Ceram. Soc., 25 (2005) 26732676.

[16] M. Grae Worster, M. Le Bars, J. Fluid Mech., 550 (2006) 149-173.

[17] C. Deslouis, M. Keddam, K. Rahmouni, H. Takenouti, F. Grasset, O. Lacroix, B. Sala, Electrochim. Acta, 56 (2011) 7890-7898.

[18] T.X. Ho, P. Kosinski, A.C. Hoffmann, A. Vik, Chem. Eng. Sci., 63 (2008) 5356-5365.

[19] D.A. Noren, M.A. Hoffman, J. Power Sources, 152 (2005) 175-181.

[20] N. Akhtar, S.P. Decent, D. Loghin, K. Kendall, Int. J. Hydrogen Energy, 34 (2009) 86458663.

[21] A. Konno, H. Iwai, K. Inuyama, A. Kuroyanagi, M. Saito, H. Yoshida, K. Kodani, K. Yoshikata, J. Power Sources, 196 (2010) 98-109.

[22] A.H.D. Cheng, D.T. Cheng, Eng. Anal. Bound. Elem., 29 (2005) 268-302.

[23] R. Suwanwarangkul, E. Croiset, M.W. Fowler, P.L. Douglas, E. Entchev, M.A. Douglas, J. Power Sources, 122 (2003) 9-18.

[24] R. Krishna, J.A. Wesselingh, Chem. Eng. Sci., 52 (1997) 861-911.

[25] M. Ni, M.K.H. Leung, D.Y.C. Leung, Energy Convers. Manage., 48 (2007) 1525-1535.

[26] J.H. Nam, D.H. Jeon, Electrochim. Acta, 51 (2006) 3446-3460.

[27] R.B. Bird, W.E. Stewart, E.N. Lightfoot, Transport Phenomena, second ed., John Wiley \& Sons, New York, 2001.

[28] B.E. Poling, J.M. Prausnitz, J.P. O'Connell, The Properties of gases and liquids, fifth ed., McGraw-Hill, New York, 2004.

[29] E. du Plessis, S. Woudberg, J. Prieur du Plessis, Chem. Eng. Sci., (2009) 2541-2551.

[30] Z. Chai, B. Shi, J. Lu, Z. Guo, Comput. Fluids, 39 (2010) 2069-2077.

[31] D. Chen, Z. Lin, H. Zhu, R.J. Kee, J. Power Sources, 191 (2009) 240-252.

[32] P. Costamagna, P. Costa, V. Antonucci, Electrochim. Acta, 43 (1998) 375-394.

[33] B.d. Darwent, National Standard Reference Data Series, Washington,. DC, United States, 1970.

[34] A. Saul, W. Wagner, J. Phys. Chem. Ref. Data, 18 (1989) 1537-1564. 
[35] W. Wagner, P. A., J. Phys. Chem. Ref. Data, 312 (2002) 387-535.

[36] R. Schmidt, W. Wagner, Fluid Phase Equilib. 19 (1985) 175-200.

[37] J.W.J. Leachman, R.T., Lemmon, E.W., J. Phys. Chem. Ref. Data, 38 (2009) 721-748. 

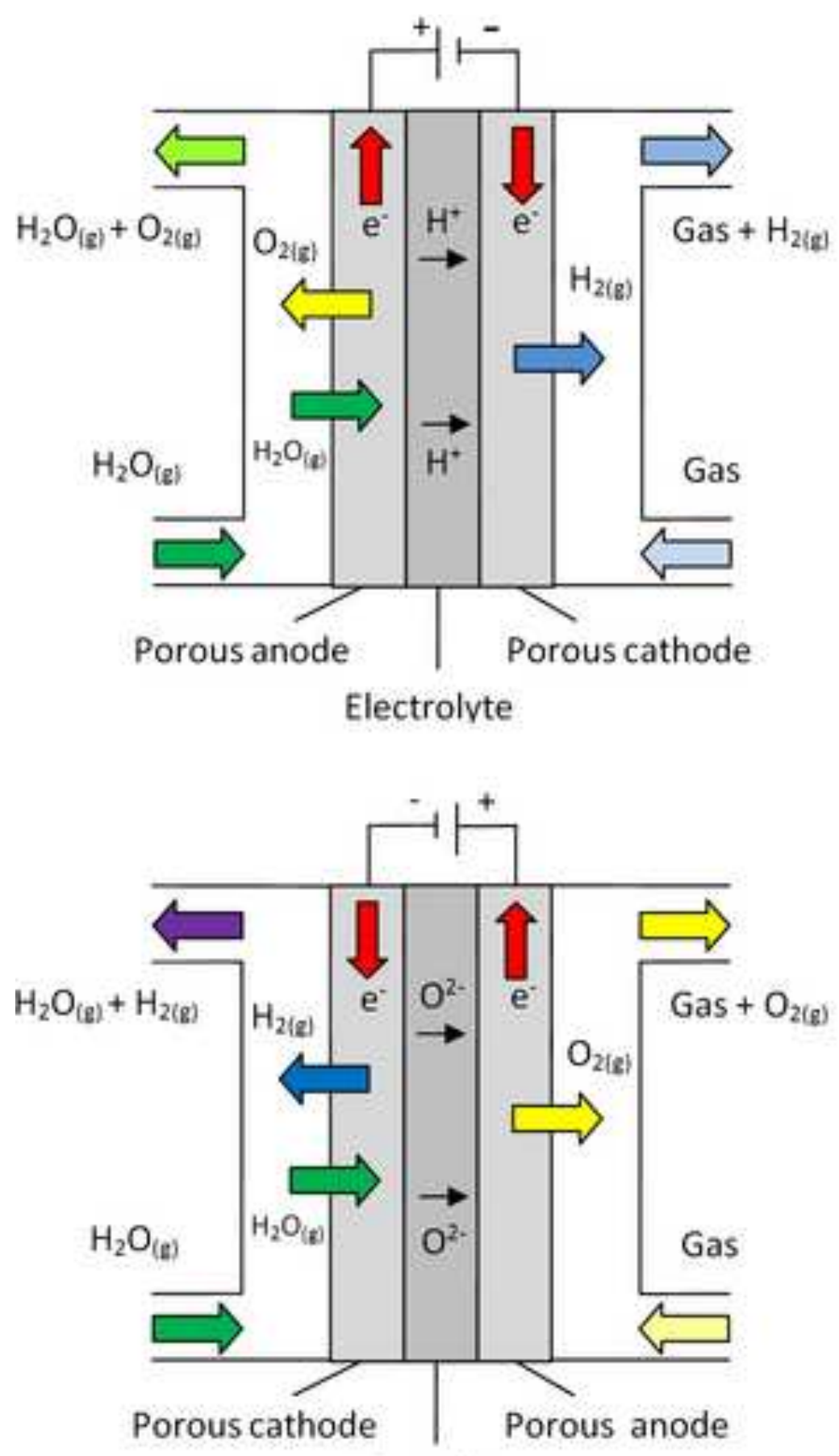

Electrolyte

\section{Proton conducting SOEC}

Oxidation:

$\mathrm{H}_{2} \mathrm{O}_{(\varepsilon)} \rightarrow 1 / 2 \mathrm{O}_{2(\mathrm{~g})}+2 \mathrm{H}^{*}+2 \mathrm{e}^{-}$

Reduction:

$2 \mathrm{H}^{+}+2 \mathrm{e}^{*} \rightarrow \mathrm{H}_{2(\mathrm{e})}$

$$
\mathrm{H}_{2} \mathrm{O}_{(\varepsilon)} \rightarrow \mathrm{H}_{2(\mathrm{~g})}+1 / 2 \mathrm{O}_{2(\mathrm{~g})}
$$

\section{Anion conducting SOEC}

Reduction

$\mathrm{H}_{2} \mathrm{O}_{(\mathrm{z})}+2 \mathrm{e}^{-} \rightarrow \mathrm{O}^{2-}+\mathrm{H}_{2(\mathrm{~g})}$

Oxidation

$\mathrm{O}^{2 \cdot} \rightarrow 1 / 2 \mathrm{O}_{2(\mathrm{z})}+2 \mathrm{e}^{2}$

$$
\mathrm{H}_{2} \mathrm{O}_{(\mathrm{k})} \rightarrow \mathrm{H}_{2(\mathrm{~g})}+1 / 2 \mathrm{O}_{2(\mathrm{~g})}
$$




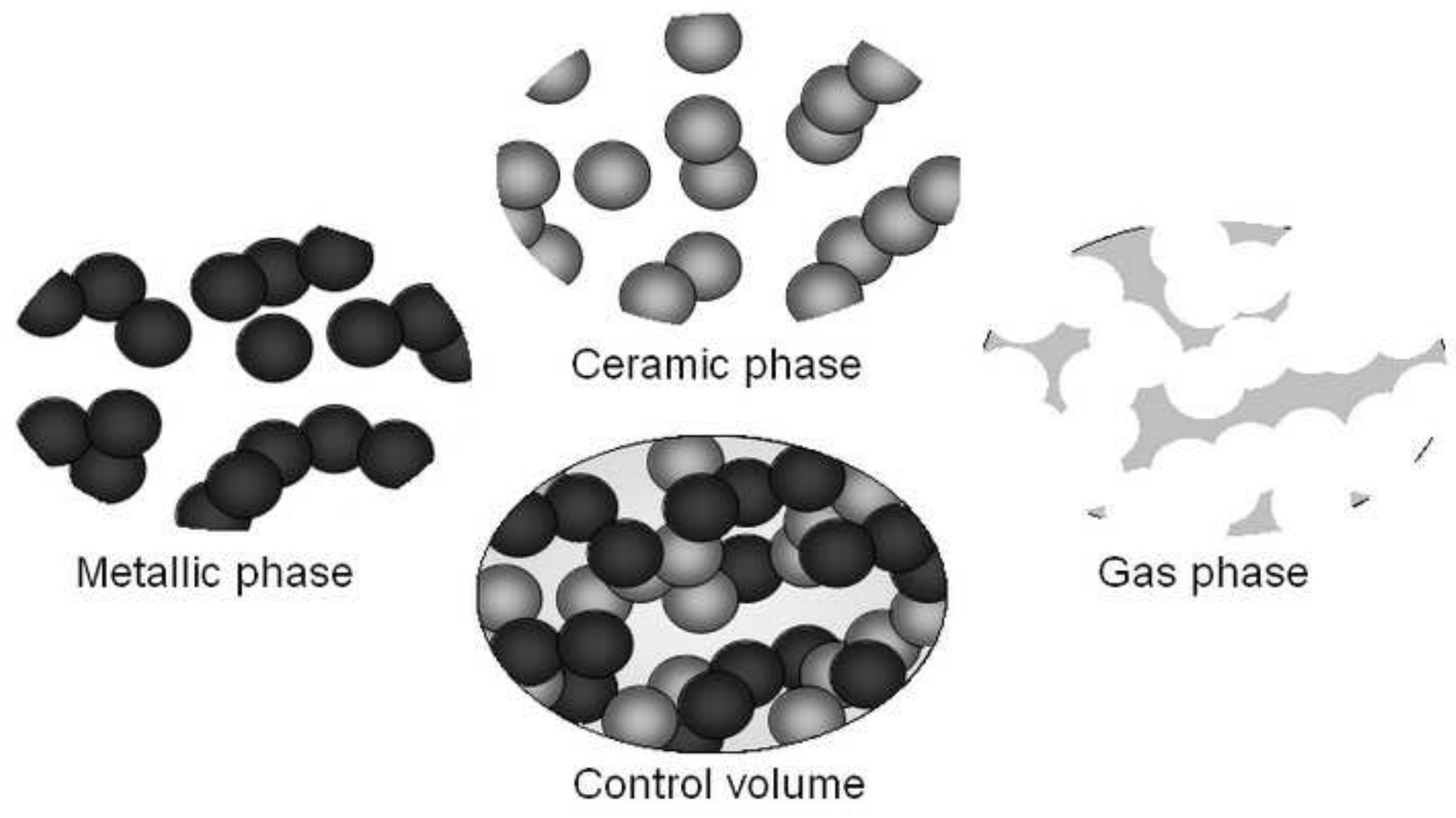




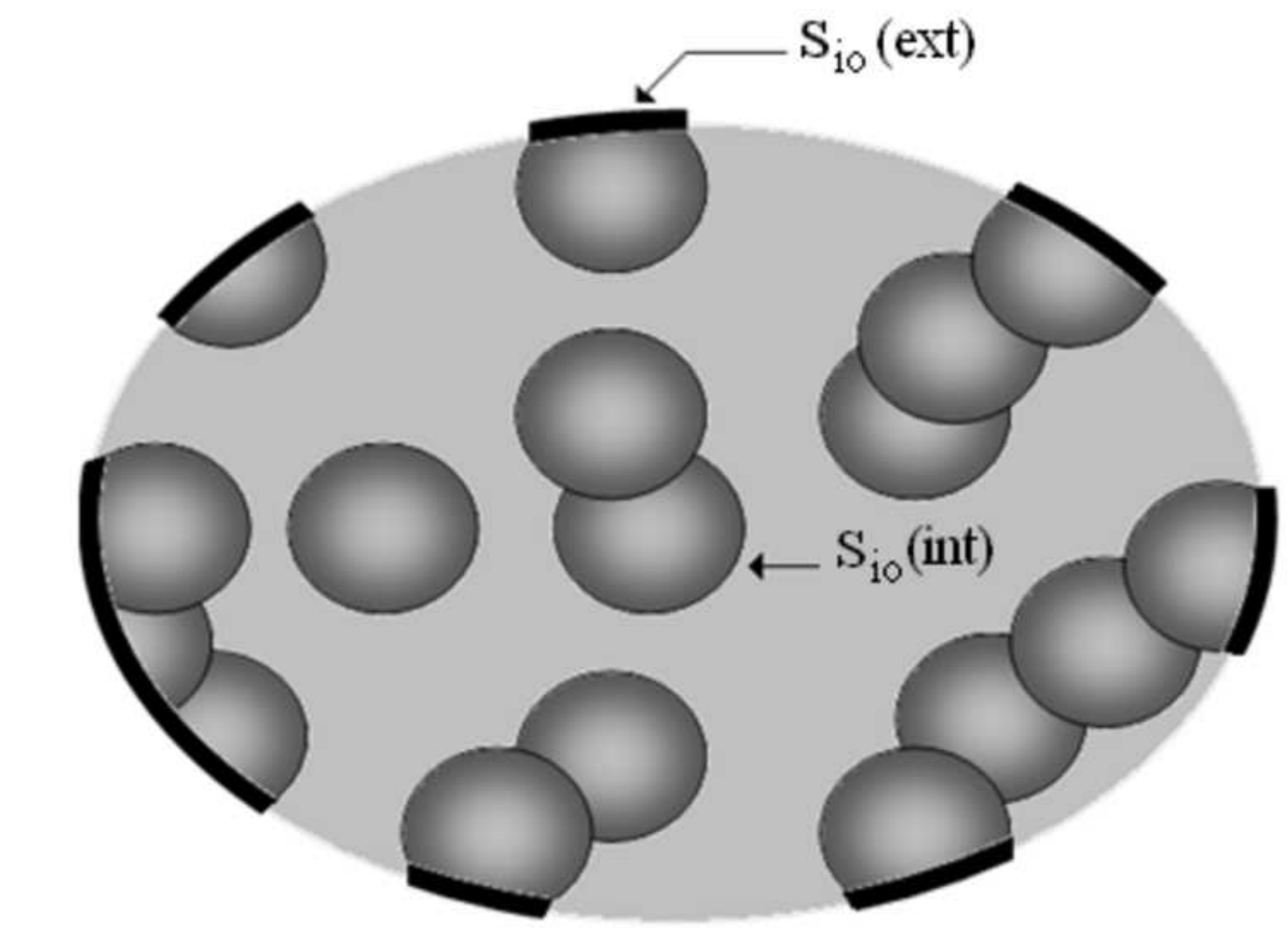

$\mathrm{S}_{\mathrm{io}}(\mathrm{ext})$
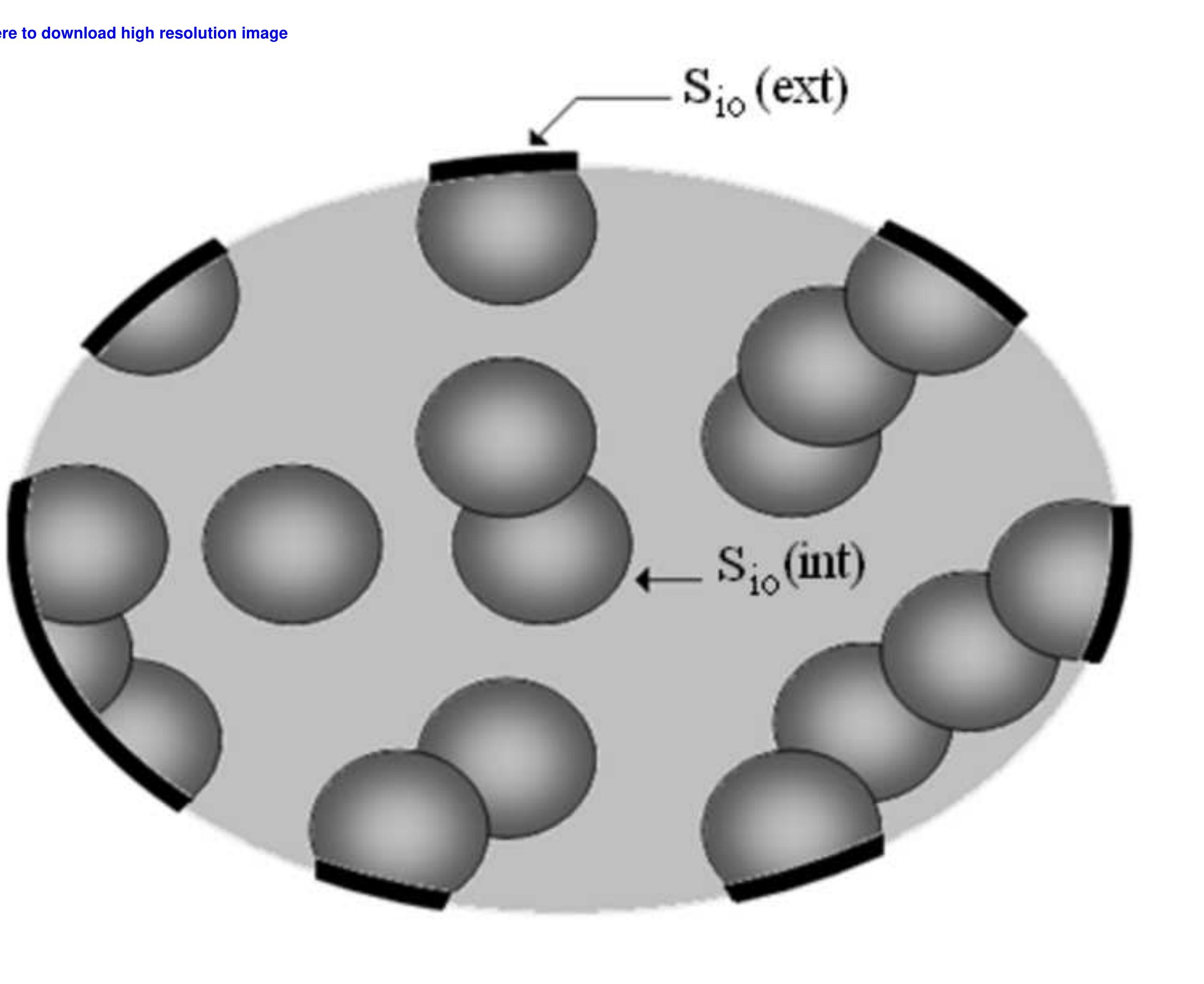


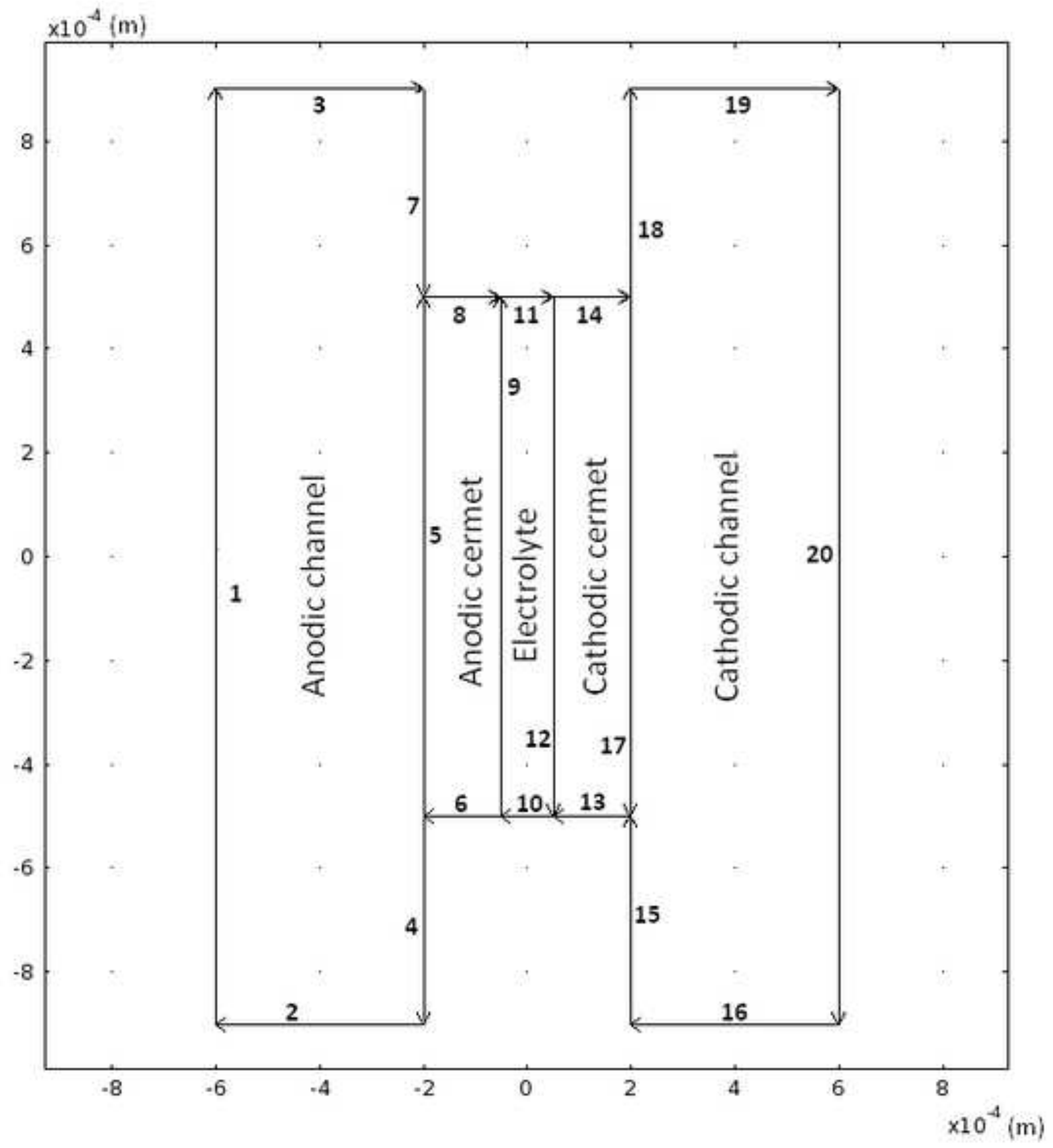




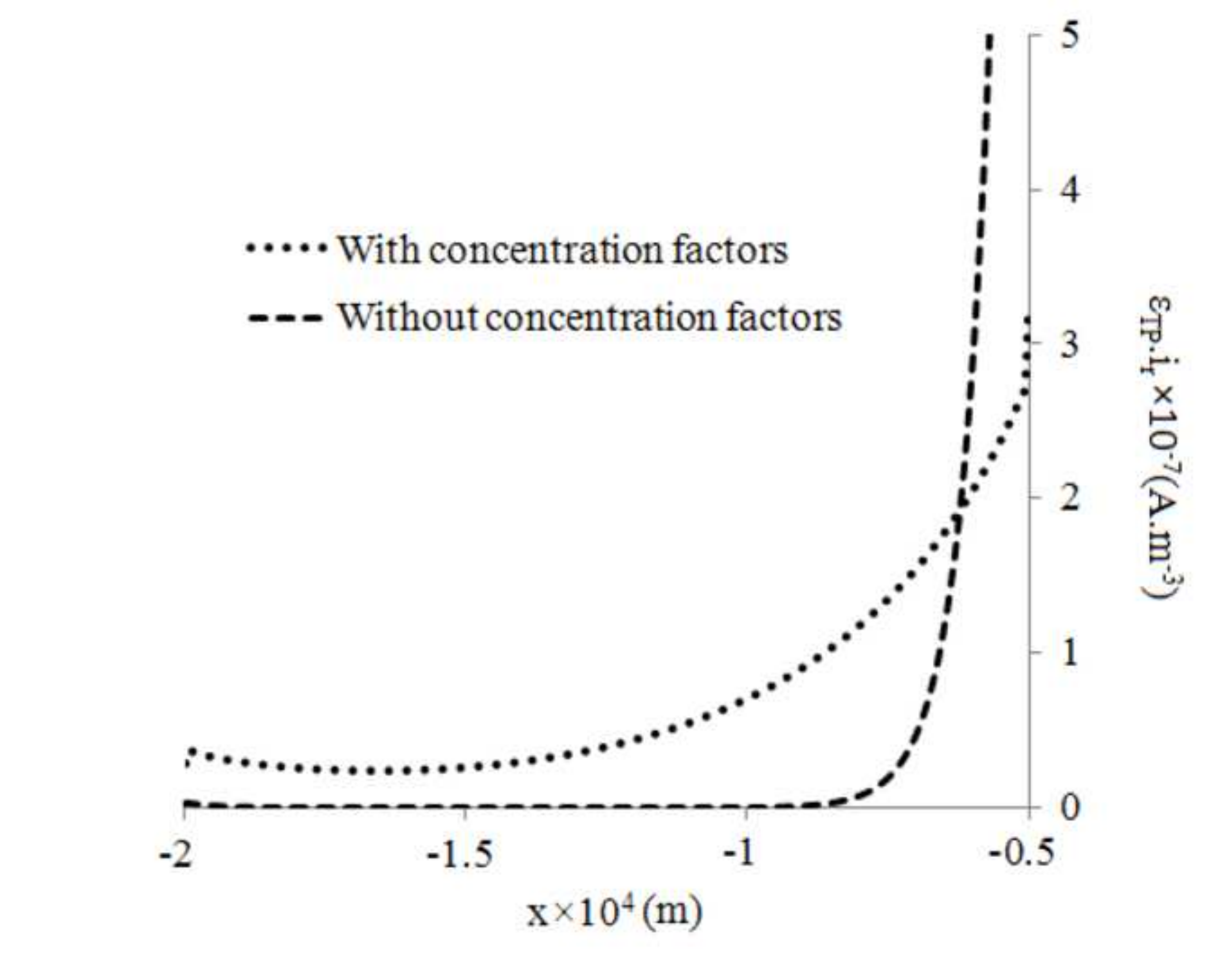

..... With concentration factors --- Without concentration factors

$$
\mathrm{x} \times 10^{4}(\mathrm{~m})
$$

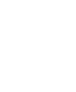


Click here to download high resolution image

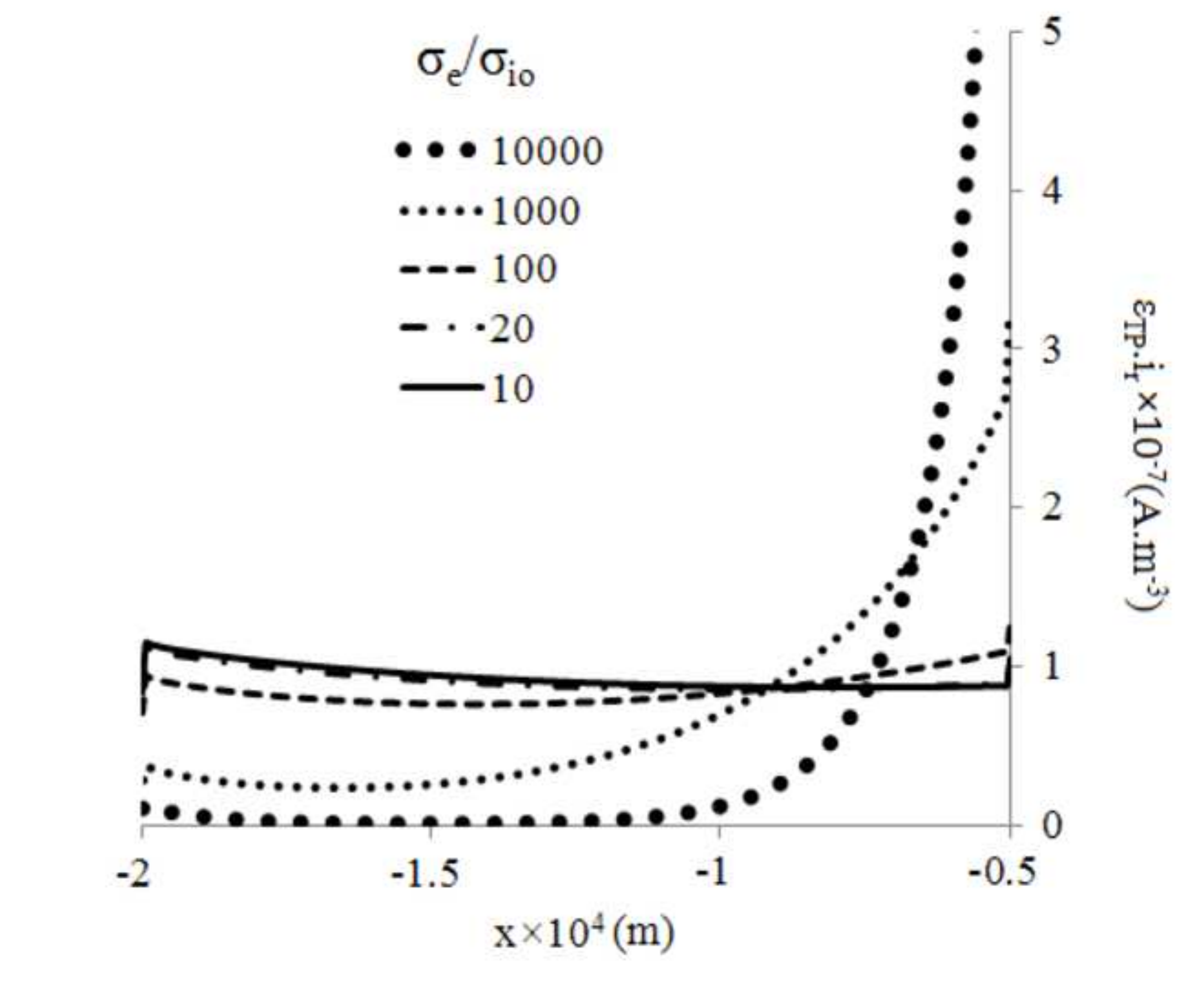

\section{here to}

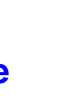

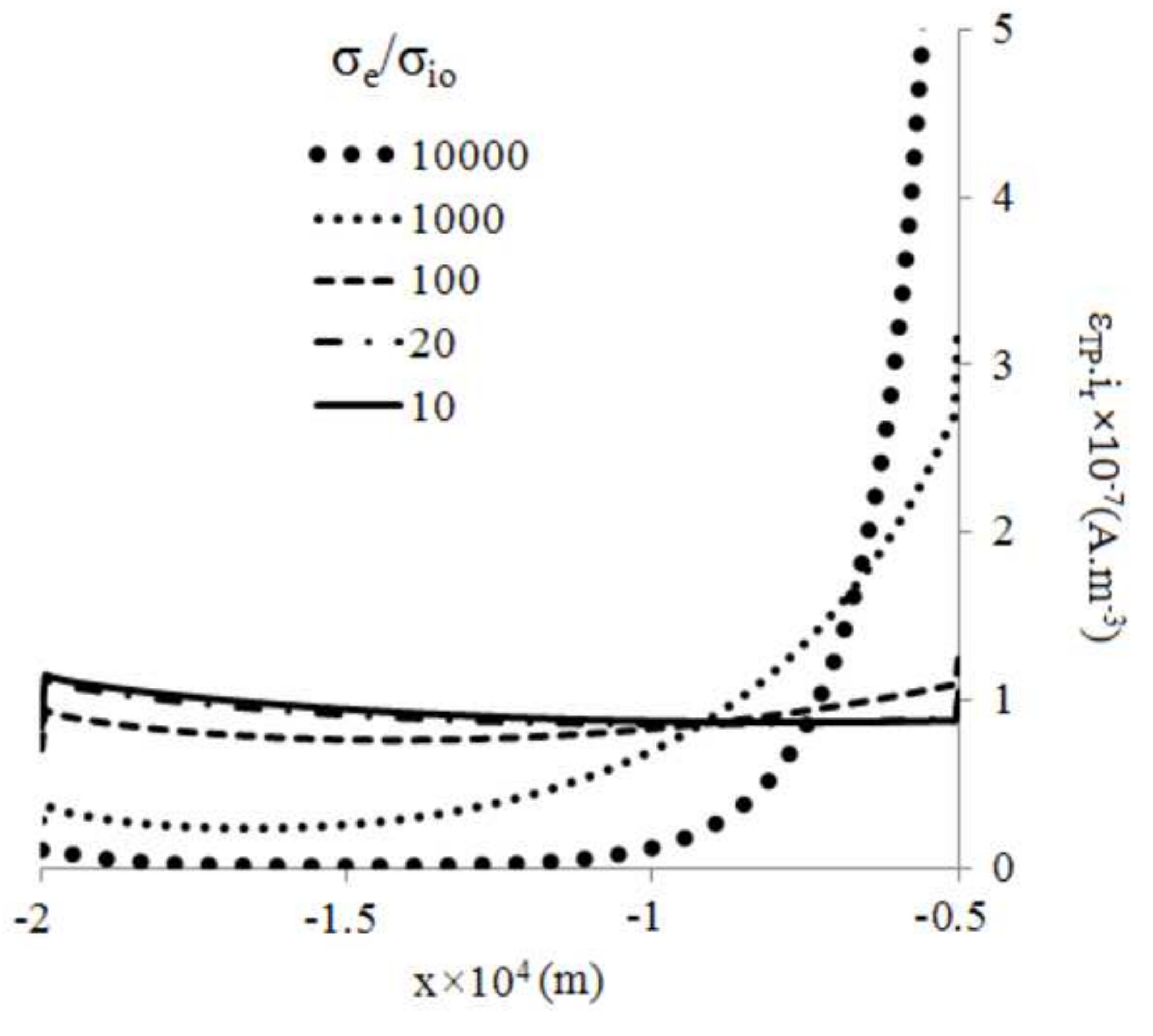

-

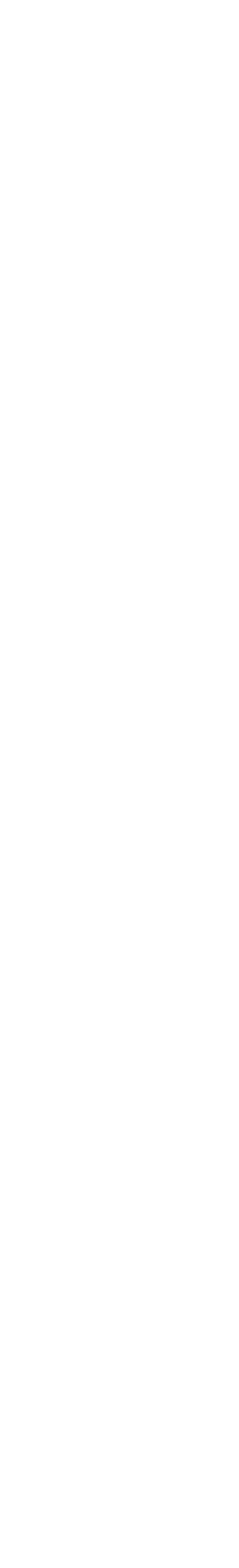

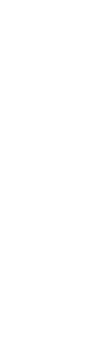




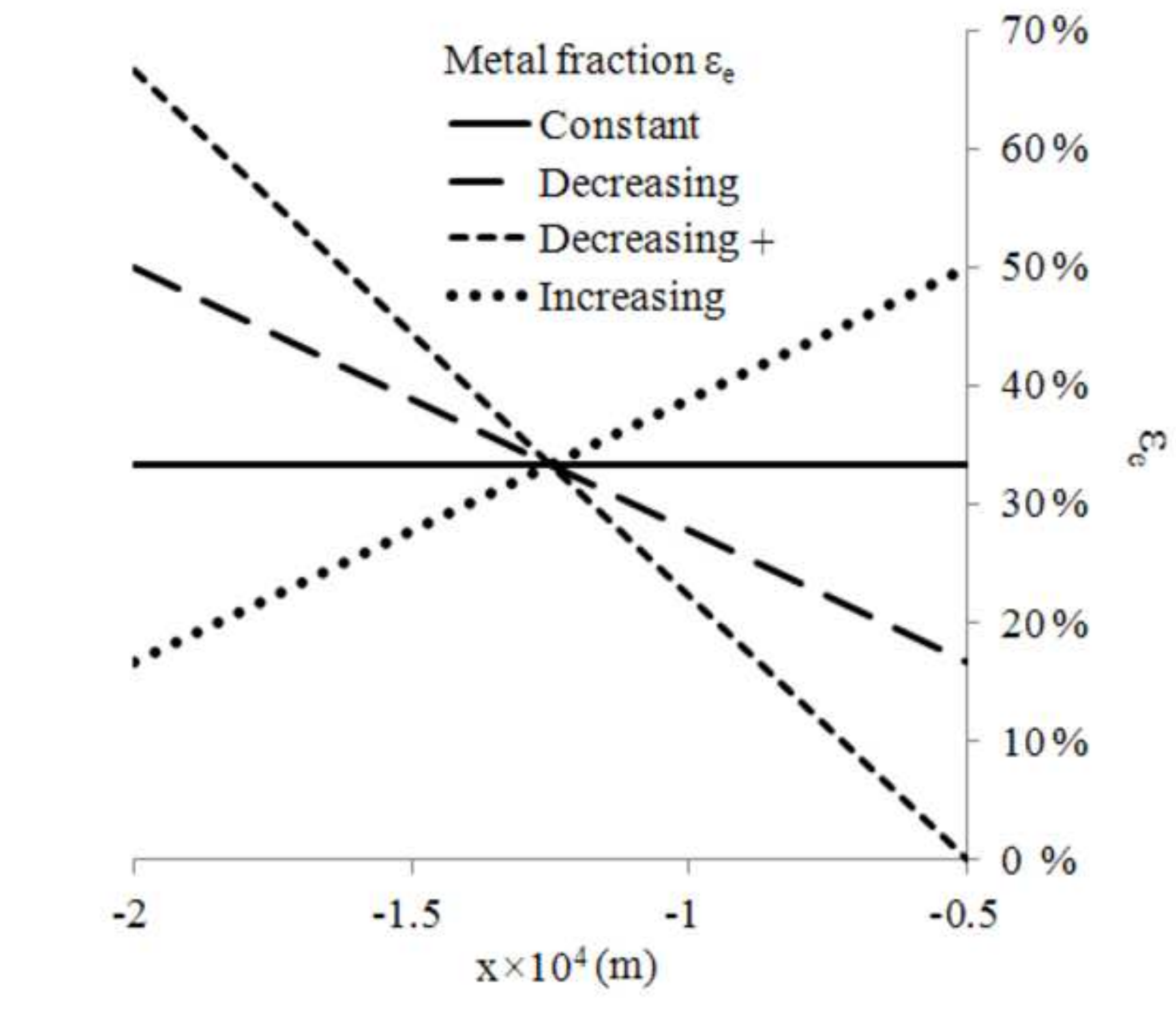

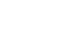


Figure

Click here to download high resolution image

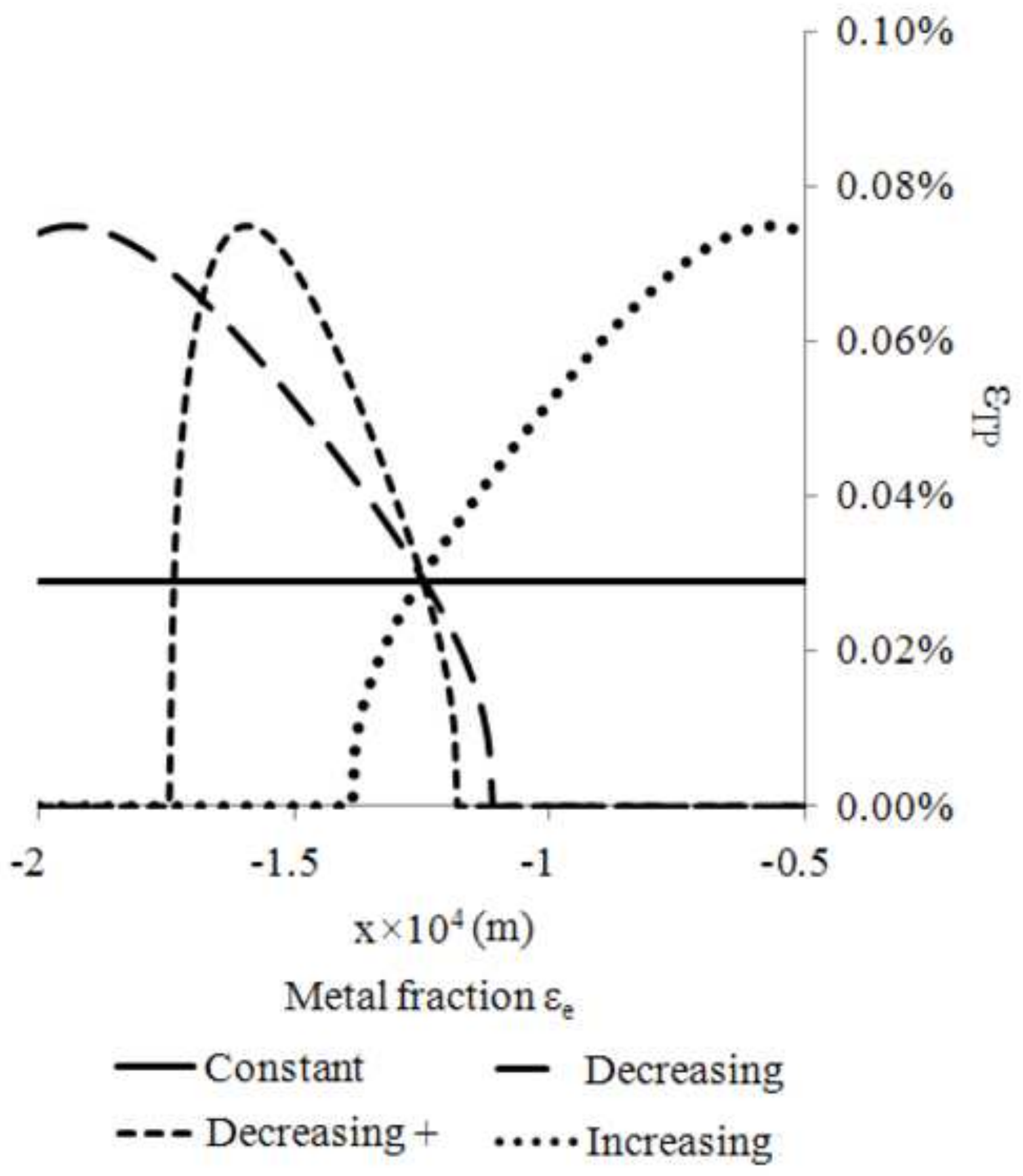


Click here to download high resolution image

Metal fraction $\varepsilon_{\mathrm{e}}$

- Constant fraction

- Decreasing fraction

--- Decreasing fraction +

$\cdots \cdot$ Increasing fraction

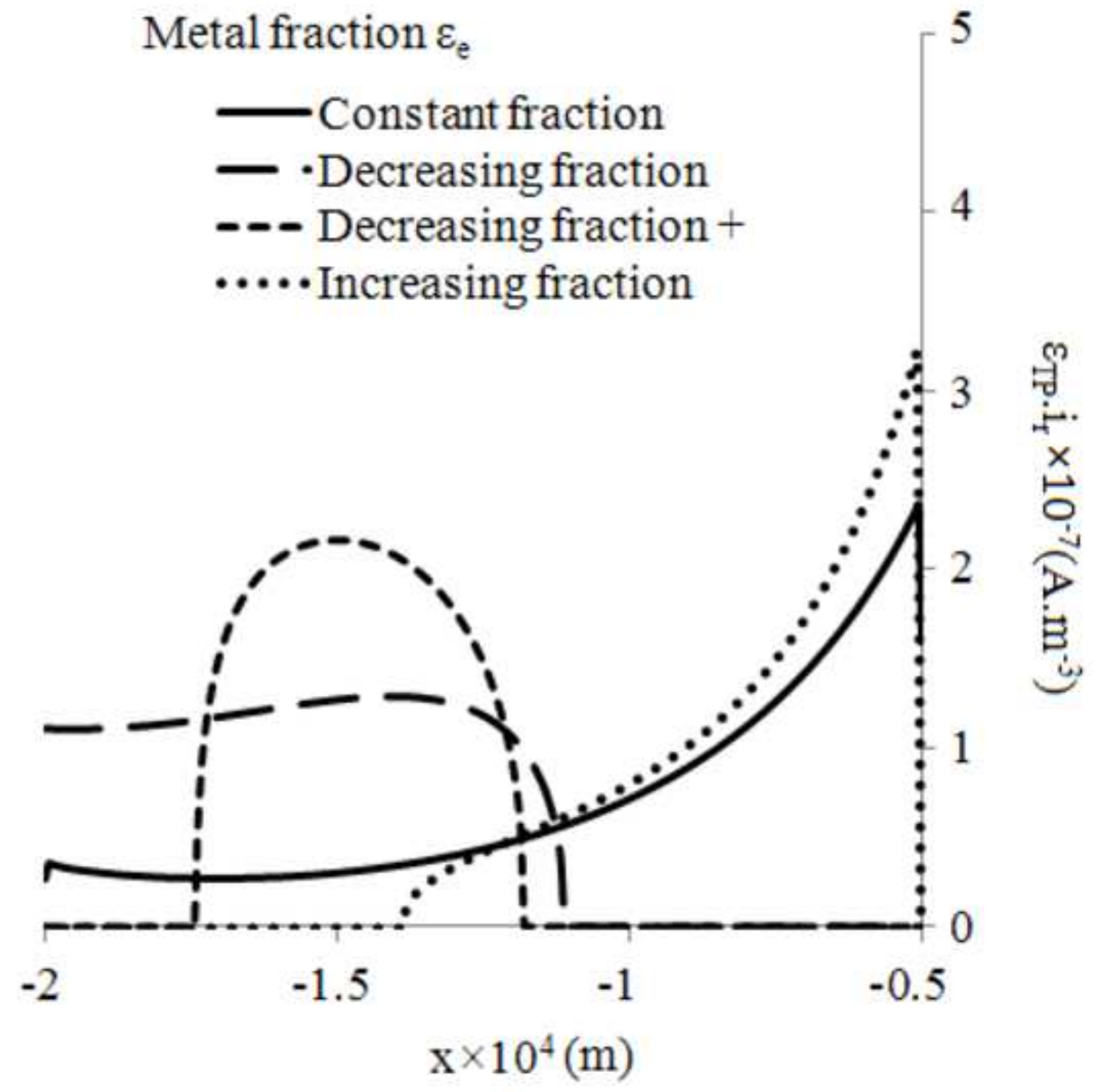




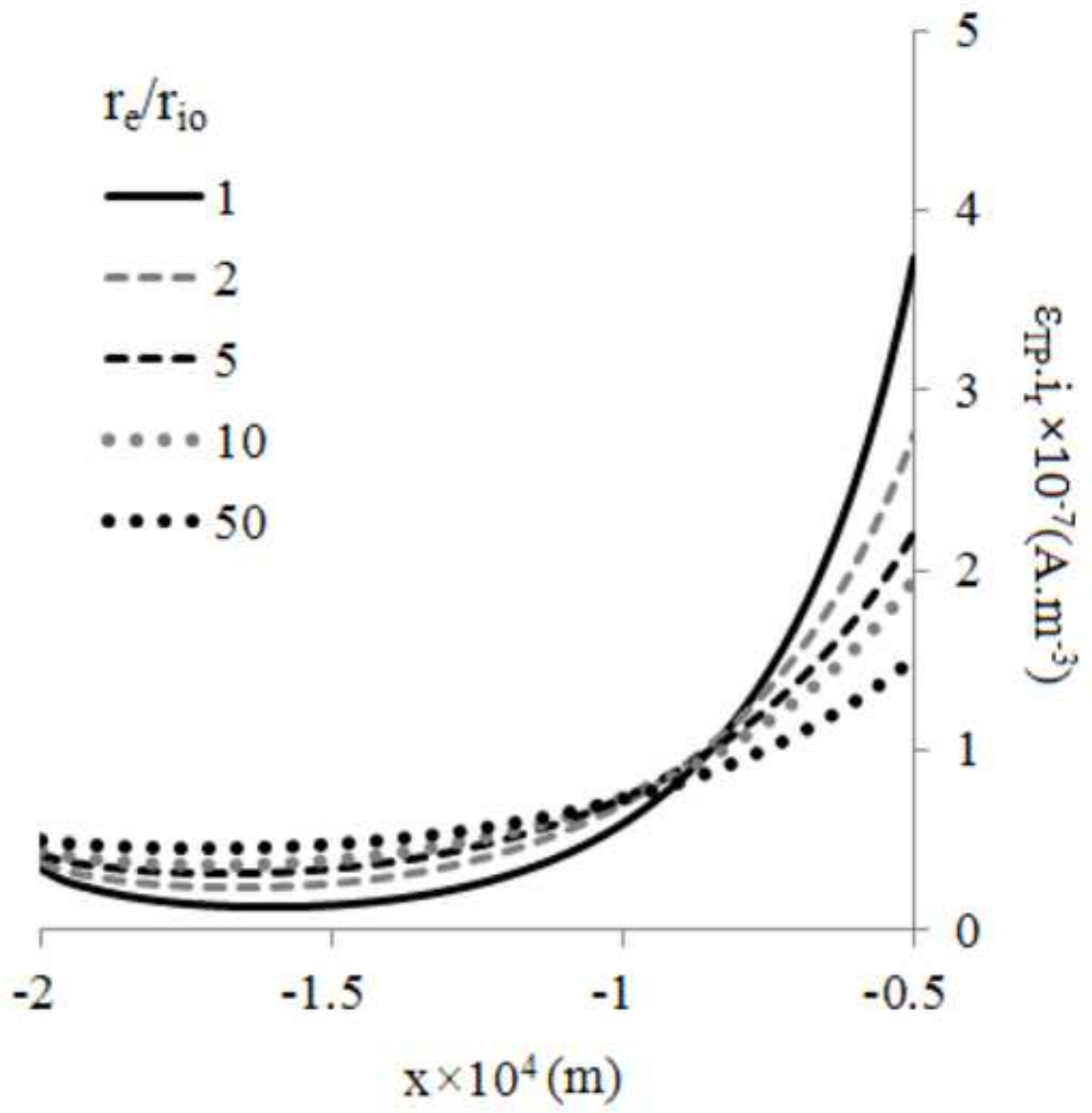



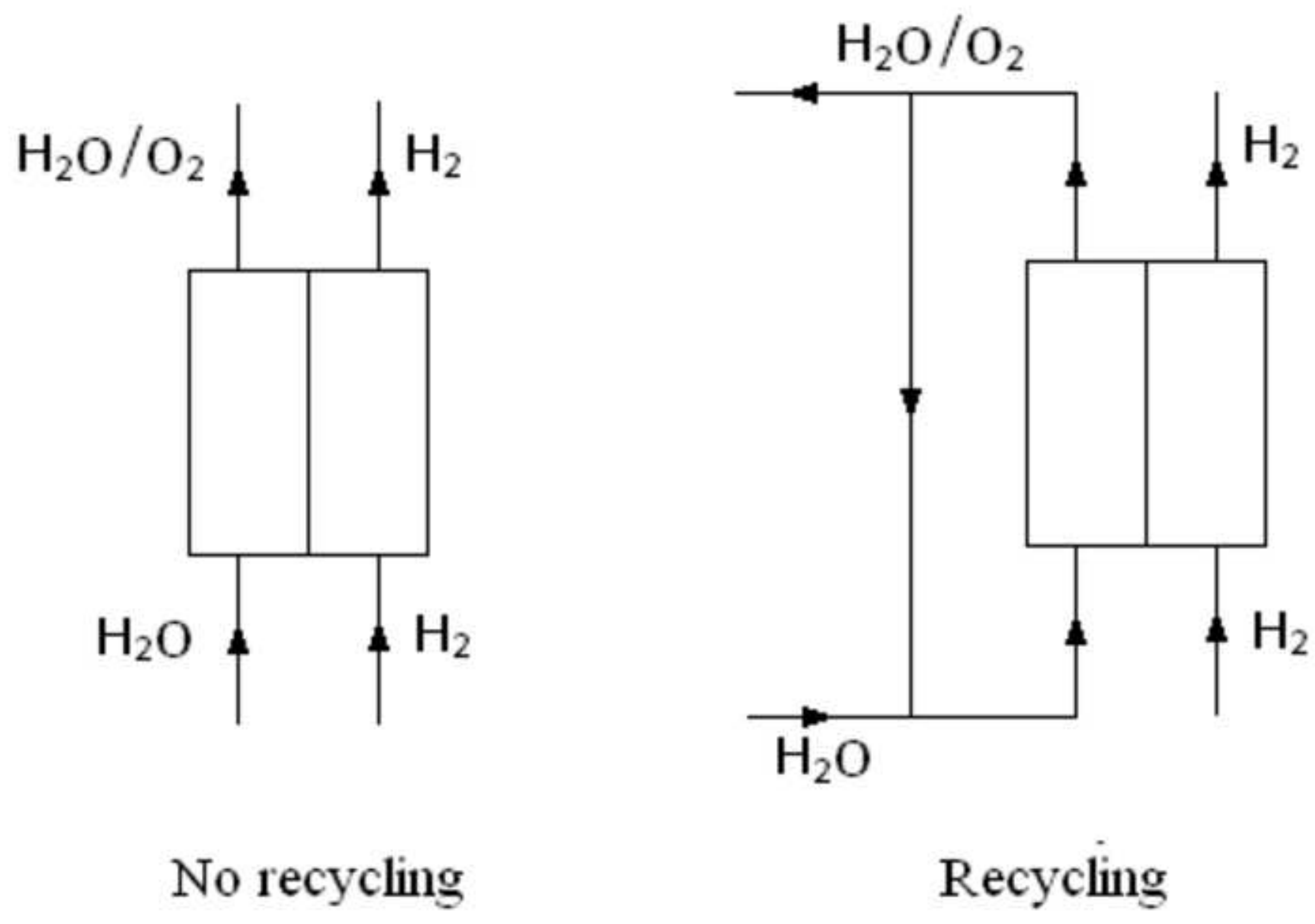

No recycling

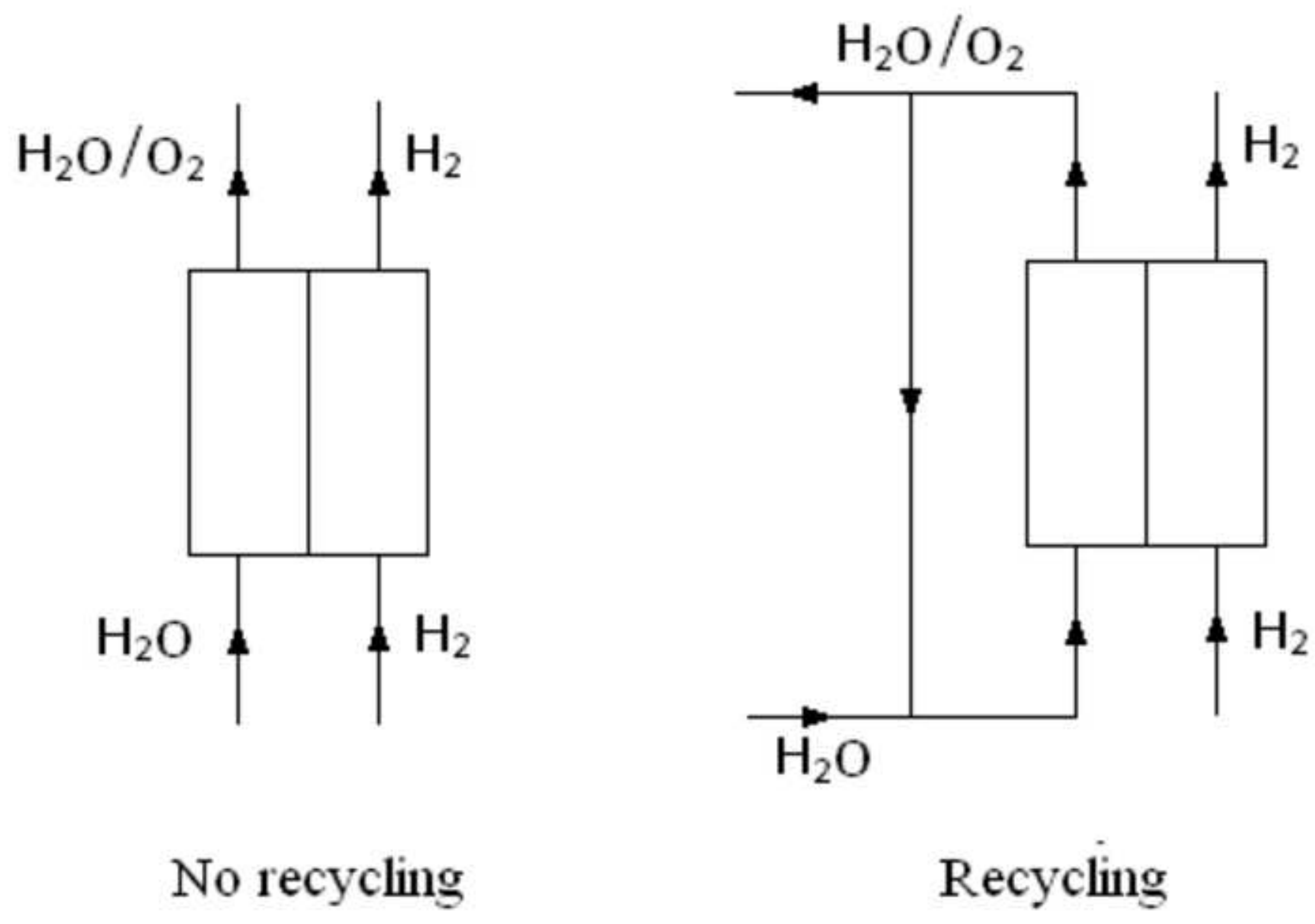


Click here to download high resolution image

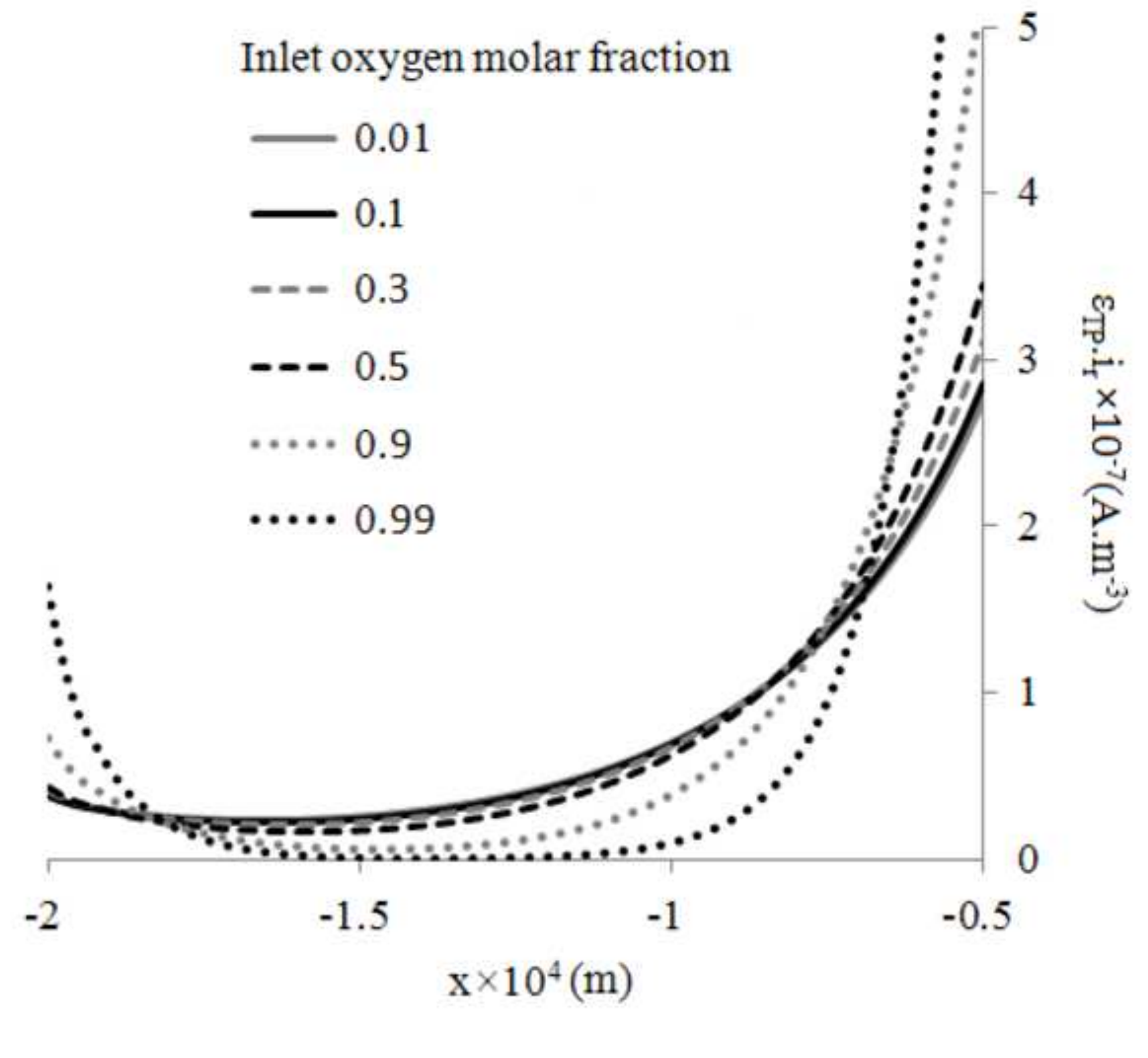




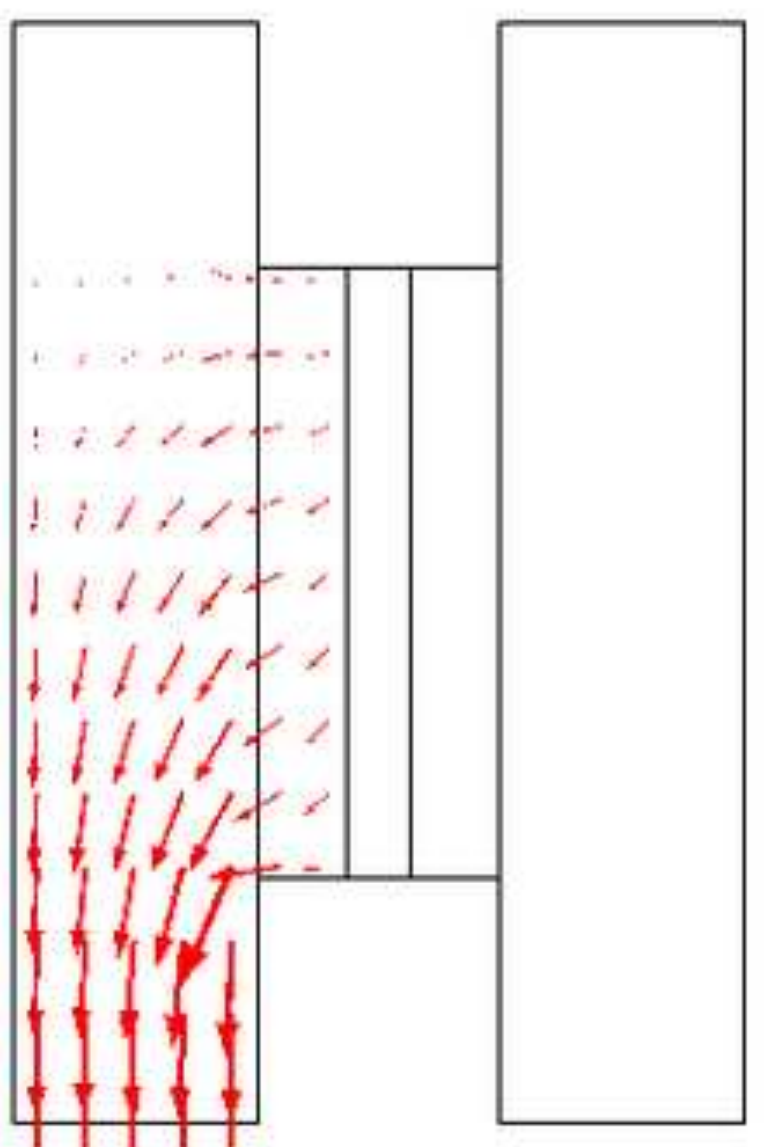

$\mathrm{Pe}=0.00035$

$\mathrm{U} 0=0.0001 \mathrm{~m} \mathrm{~s}^{-1}$

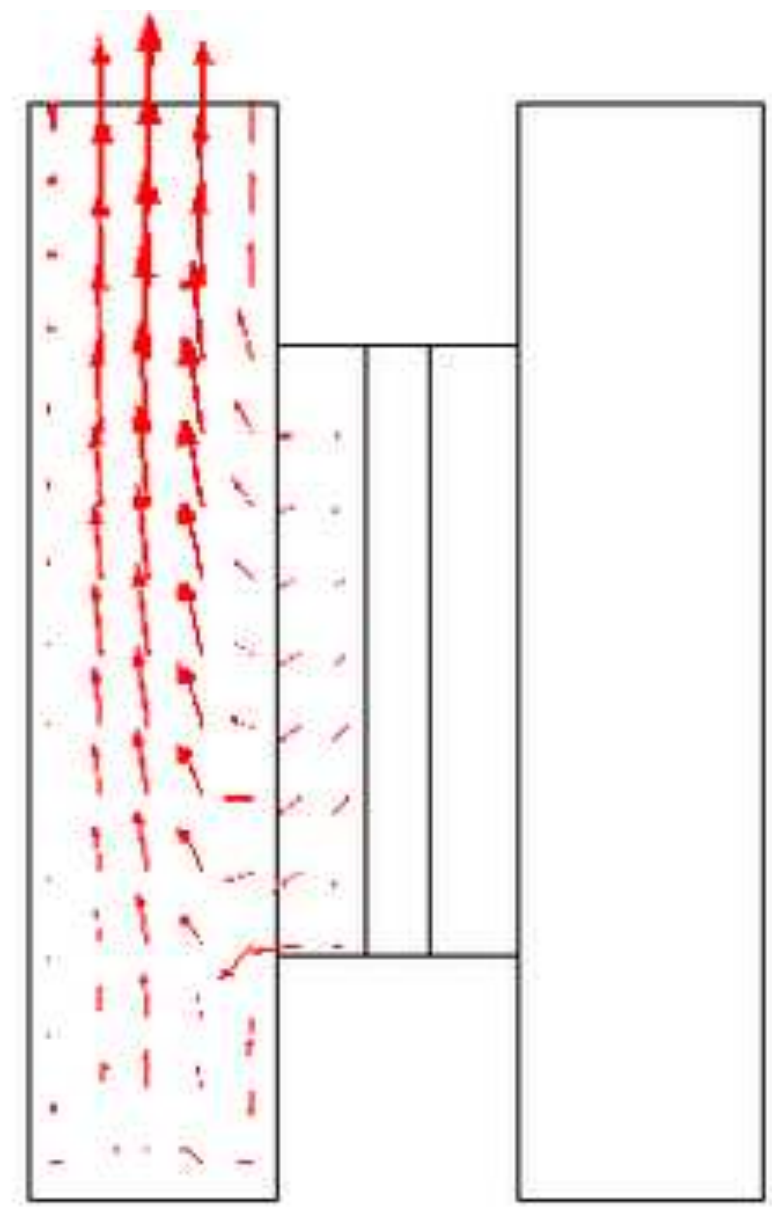

$\mathrm{Pe}=0.0175$

$\mathrm{U} 0=0.005 \mathrm{~m} \mathrm{~s}^{-1}$

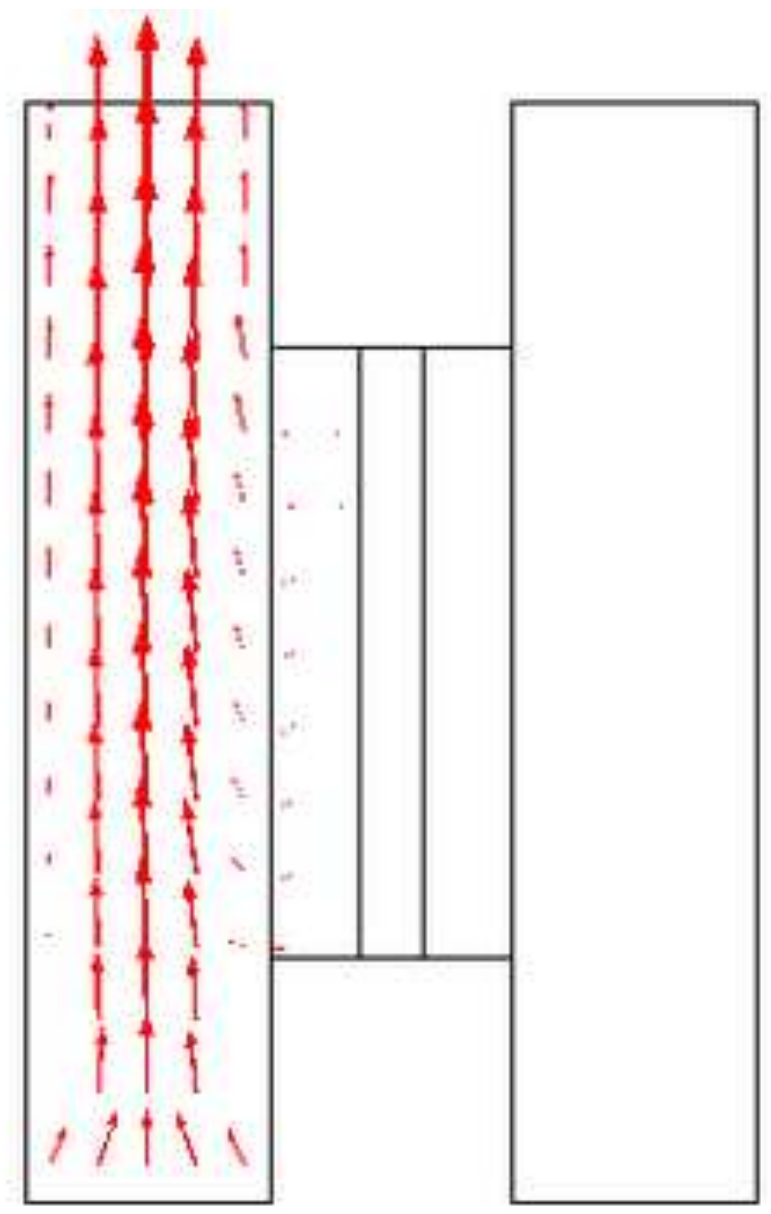

$\mathrm{Pe}=0.035$

$\mathrm{U} 0=0.01 \mathrm{~ms}^{-1}$ 
Figure 1. Principle of proton conducting and anion conducting SOECs.

Figure 2. Control volume as a sum of single phase volumes.

Figure 3. Internal and external surface of the ionic conductor.

Figure 4. Electrolyser regions and boundaries.

Figure 5. Effect of concentration coefficients in Butler-Volmer equation on oxygen production across the anodic cermet. X-axis: position in the anodic cermet (on the left the anodic channel, on the right the electrolyte). Y-axis: transfer current density multiplied by the specific reactive volume.

Figure 6. Effect of conductivity ratios on oxygen production across the anodic cermet. Xaxis: position in the anodic cermet (on the left the anodic channel, on the right the electrolyte). Y-axis: transfer current density multiplied by the specific reactive volume.

Figure 7. Presentation of the different metal volume fractions along the anodic cermet tested. X-axis: position in the anodic cermet (on the left the anodic channel, on the right the electrolyte). Y-axis: metal volume fraction.

Figure 8. Profile of specific reactive volume along the anodic cermet respect to the metal fraction. X-axis: position in the anodic cermet (on the left the anodic channel, on the right the electrolyte). Y-axis: specific reactive volume.

Figure 9. Effect of metal fraction on oxygen production along the anodic cermet. X-axis: position in the anodic cermet (on the left the anodic channel, on the right the electrolyte). Yaxis: transfer current density multiplied by the specific reactive volume.

Figure 10. Effect of radius ratio on oxygen production along the anodic cermet. X-axis: position in the anodic cermet (on the left the anodic channel, on the right the electrolyte). Yaxis: transfer current density multiplied by the specific reactive volume.

Figure 11. Configuration for steam recycling 
Figure 12. Effect of inlet oxygen molar fraction on oxygen production along the anodic cermet. X-axis: position in the anodic cermet (on the left the anodic channel, on the right the electrolyte). Y-axis: transfer current density multiplied by the specific reactive volume.

Figure 13. Oxygen flux vectors and Peclet number along the anode showing counter diffusion of oxygen back to the inlet which is located at the ordinate $\mathrm{Y}=-9 \times 10^{-4} \mathrm{~m}$. 
Table 1

Reactor dimensions

\begin{tabular}{ll}
\hline Parameter & Value \\
\hline Anodic channel width & $4 \times 10^{-4} \mathrm{~m}$ \\
Anodic cermet width & $1.5 \times 10^{-4} \mathrm{~m}$ \\
Electrolyte width & $1 \times 10^{-4} \mathrm{~m}$ \\
Cathodic cermet width & $1.5 \times 10^{-4} \mathrm{~m}$ \\
Cathodic channel width & $4 \times 10^{-4} \mathrm{~m}$ \\
Anodic cermet length & $10^{-3} \mathrm{~m}$ \\
Electrolyte length & $10^{-3} \mathrm{~m}$ \\
Cathodic cermet length & $10^{-3} \mathrm{~m}$ \\
Anodic channel length & $1.8 \times 10^{-3} \mathrm{~m}$ \\
Cathodic channel length & $1.8 \times 10^{-3} \mathrm{~m}$
\end{tabular}

Table 2

Boundary conditions

\begin{tabular}{llll}
\hline Boundary & Species transport & Momentum transport & Charge transport \\
\hline 1 & Zero flux & Wall - No slip & - \\
2 & Inflow - concentration & Velocity inlet & - \\
3 & Outflow & Outlet - Pressure & - \\
4 & Zero flux & Wall - No slip & - \\
5 & - & - & Ionic : Zero Flux \\
& & & Electronic : Flux \\
$6,8,10,11,13,14$ & Zero flux & Wall - No slip & Zero flux \\
$7,9,12,15$ & Zero flux & Wall - No slip & - \\
16 & Outflow & Outlet - Pressure & - \\
17 & - & - & Ionic : Zero Flux \\
& & & Electronic : Flux \\
18 & Zero flux & Wall - No slip & - \\
19 & Inflow - concentration & Velocity inlet & - \\
20 & Zero flux & Wall - No slip & -
\end{tabular}

Table 3

Constants

\begin{tabular}{llll}
\hline Parameter & Value & Unit & Reference \\
\hline Ideal gas constant & 8.314 & $\mathrm{~J} \mathrm{~mol}^{-1} \mathrm{~K}^{-1}$ & {$[27]$} \\
Faraday's constant & 96485 & $\mathrm{C} \mathrm{mol}^{-1}$ & -
\end{tabular}




$\begin{array}{llll}\text { Dynamic viscosity for steam } & 3 \times 10^{-5} & \mathrm{~Pa} \mathrm{~s} & {[36]} \\ \text { Dynamic viscosity for hydrogen } & 1.85 \times 10^{-5} & \mathrm{~Pa} \mathrm{~s} & {[38]} \\ \text { Exchange current density } & 10^{12} & \mathrm{~A} \mathrm{~m}^{-3} & {[11,13,18]} \\ \text { Arbitrary specific reactive volume (electrolyte) } & 1 \times 10^{-18} & - & - \\ \pi & 3.1415 & - & - \\ \text { Boltzmann's constant } & 1.38 \times 10^{-23} & \mathrm{~J} \mathrm{~K}^{-1} \mathrm{~kg}^{-1} & {[27]} \\ \text { Stoichiometry coefficient (Oxygen) } & 0.25 & - & - \\ \text { Stoichiometry coefficient (Water) } & -0.5 & - & - \\ \text { Stoichiometry coefficient (Hydrogen) } & 0.5 & - & - \\ \text { Number of charge (ion) } & 1 & - & - \\ \text { Molar mass (Hydrogen) } & 0.002 & \mathrm{~kg} \mathrm{~mol}^{-1} & - \\ \text { Molar mass (Steam) } & 0.018 & \mathrm{~kg} \mathrm{~mol}^{-1} & - \\ \text { Molar mass (Oxygen) } & 0.032 & \mathrm{~kg} \mathrm{~mol}^{-1} & - \\ \text { Molar mass (Ion) } & 0.001 & \mathrm{~kg} \mathrm{~mol}^{-1} & - \\ \text { Lenard-Jones coefficient (Oxygen) } & 1.48 \times 10^{-21} & \mathrm{~J} & {[27]} \\ \text { Lenard-Jones coefficient (Water) } & 7.90 \times 10^{-21} & \mathrm{~J} & {[27]} \\ \text { Lenard-Jones coefficient (Hydrogen) } & 5.25 \times 10^{-22} & \mathrm{~J} & {[27]} \\ \text { Collision diameter (Oxygen) } & 0.346 \times 10^{-9} & \mathrm{~m} & {[27]} \\ \text { Collision diameter (Water) } & 0.261 \times 10^{-9} & \mathrm{~m} & {[27]} \\ \text { Collision diameter (Hydrogen) } & 0.292 \times 10^{-9} & \mathrm{~m} & {[27]} \\ \text { Mean coordination number } & 6 & - & {[31]} \\ \text { Gibbs enthalpy for water formation } & -200 \times 10^{3} & \mathrm{~J} \mathrm{~mol} & {[36]}\end{array}$

\section{Table 4}

Values of variable parameters and inlet parameters for the reference calculation

\begin{tabular}{llll}
\hline Parameter & Reference value & Unit & Other values tested \\
\hline Inlet current density & 1000 & $\mathrm{~A} \mathrm{~m}^{-2}$ & - \\
Ionic conductivity (ceramic) & 1 & $\mathrm{~S} \mathrm{~m}^{-1}$ & $0.110,50,100$ \\
Electronic conductivity (metal) & 1000 & $\mathrm{~S} \mathrm{~m}^{-1}$ & - \\
Particle radius (metal) & $10^{-6}$ & $\mathrm{~m}$ & $2 \times 10^{-6}, 5 \times 10^{-6}, 10 \times 10^{-6}, 50 \times 10^{-6}$ \\
Particle radius (ceramic) & $5 \times 10^{-7}$ & $\mathrm{~m}$ & - \\
Initial oxygen molar fraction & 0,01 & - & $0.1,0.3,0.5,0.9$ \\
Operating pressure & $10^{6}$ & $\mathrm{~Pa}$ & $20 \times 10^{-6}, 30 \times 10^{-6}$ \\
Operating temperature & 873 & $\mathrm{~K}$ & -
\end{tabular}




\section{Meng Ni (倪萌 博士)}

Assistant Professor

Coordinator, Building Energy Research Group

Tel.: (852) - 27664152

E-mail address: bsmengni@polyu.edu.hk

\section{M.M Hussain}

Department of Mechanical and Mechatronics Engineering, University of Waterloo, Waterloo, Ontario, Canada N2L 3G1

E-mail address: mmhussain@uwaterloo.ca

\section{Anchasa Pramuanjaroenkija}

Department of Mechanical and Aerospace Engineering, University of Miami, Coral Gables, FL 33124, USA

Tel.: +1 305284 2571; fax: +1 3052842580 .

E-mail address: anchasa@gmail.com 